Please note that this is the accepted version of this manuscript, and the published article may differ.

Reference: Kruk, M. \& Matsick, J. L. (2021). A taxonomy of identity safety cues based on gender and race: From a promising past to an intersectional and translational future. Translational Issues in Psychological Science. Online ahead of print. https://doi.org/10.1037/tps0000304

\title{
A Taxonomy of Identity Safety Cues Based on Gender and Race: \\ From a Promising Past to an Intersectional and Translational Future

$$
\text { Mary Kruk }{ }^{1,2} \text { and Jes L. Matsick }{ }^{1,2}
$$

${ }^{1}$ Department of Psychology, The Pennsylvania State University, University Park, PA, USA

${ }^{2}$ Department of Women's, Gender, and Sexuality Studies, The Pennsylvania State University, University Park, PA, USA

\section{Author Note}

Mary Kruk ORCID: https://orcid.org/0000-0003-3537-0362

Jes L. Matsick ORCID: https://orcid.org/0000-0003-4368-3211

Correspondence should be addressed to Mary Kruk, M.S. at the Department of Psychology, The Pennsylvania State University, 527 Moore Building, University Park, PA 16801. Email: mxk724@psu.edu

We thank Drs. Stephanie Shields, José Soto, and Britney Wardecker for their helpful feedback on an early version of this manuscript. 


\begin{abstract}
Identity safety cues refer to aspects of the environment or social setting that communicate one is valued and the threat of discrimination is limited. In this article, we review the content of identity safety cues, their strengths and limitations, and implications for future theory, research, and practice. A close analysis of the identity safety cue literature can inform the efforts of individuals and organizations who aim to enhance social inclusion and promote diversity. Searching databases for safety cue research (e.g., Google Scholar, PsycINFO), we found more than 35 peer-reviewed articles that explicitly addressed identity safety cues. We synthesized the literature to produce a novel taxonomy of identity safety cues that target stigmatized groups, namely those minoritized by gender and race. A taxonomy of identity safety cues can facilitate clear and universal communication about the science, delineate types of operational definitions, and direct future research and theorizing. Our review revealed that knowledge of cues is often limited by unidimensional identity characteristics (i.e., targeting gender or race, not both), and we discovered four cue categories that induced identity safety: minority representation, diversity philosophies and programming, environmental features, and identity-safe information. The significance of this review is that, beyond establishing the only known taxonomy of identity safety cues, we critically examine the strengths and weaknesses of cue efficacy and provide a forward-thinking discussion of theoretical implications and broader impacts, focusing on the expansion of intersectionality theorizing and the translation of identity safety cue research.
\end{abstract}

Keywords: situational cues, safety, threat, social identity, stigma, diversity and inclusion 


\section{Public Significance Statement}

This article accelerates knowledge for creating environments that make minoritized groups feel welcomed, valued, and protected from stigmatization. We found that the scientific literature provides four categories of effective identity safety cues (i.e., aspects of settings that communicate support and safety from stigma): having other minoritized people present, stating commitments to diversity, displaying physical features that signal inclusive norms and values, and providing information that conveys fair and positive expectations. 


\section{A Taxonomy of Identity Safety Cues Based on Gender and Race: \\ From a Promising Past to an Intersectional and Translational Future}

In the era of \#MeToo, Black Lives Matter, and the post-2016 U.S. Presidential election of Donald Trump, individuals and organizations have demonstrated strong commitment to promoting social inclusion and diversity (Cahan, 2020; Chamberlain, 2019; Washington \& Newport, 2017). To that end, multiple broad approaches exist (see Kalev et al., 2006; Onyeador et al., 2021; Steele, 2010) to lessen biases among members of dominant groups (e.g., those advantaged by race, gender, or sexual orientation) and to increase inclusion among members of stigmatized groups (e.g., those disadvantaged by their social identities). Extensive reviews already detail "what works" and does not work in terms of bias and diversity trainings (e.g., Bezrukova et al., 2016; Carter et al., 2020; Chang et al., 2019; Onyeador et al., 2021), prejudice reduction strategies (e.g., Lai et al., 2014; Legault et al., 2011; Paluck et al., 2021), and other diversity-related initiatives (e.g., Brannon et al., 2018; Kaiser et al., 2013; Kalev et al., 2006). Likewise, a substantial volume of research identifies the conditions under which people with devalued social identities anticipate stigma and encounter threats to psychological well-being (e.g., belonging, trust, motivation; Branscombe et al., 1999; Emerson \& Murphy, 2014; Murphy \& Taylor, 2012; Pennington et al., 2016; Spencer et al., 2016; Steele, 1997; Steele et al., 2002). Both scientific efforts-toward a deeper understanding of bias and anticipated threat-serve significant roles in informing social inclusion and diversity initiatives.

We propose that individuals and organizations seeking to enrich inclusion and diversity and lessen social identity threat (i.e., the undermining of a social group's value; Branscombe et al., 1999) may benefit from intentional use of situational cues. Situational cues are features of a setting or situation that signal the likelihood of how one will be treated (i.e., by conveying the possibility of stigma; Murphy et al., 2007; Murphy \& Taylor, 2012). A particular type of situational cue, called an identity safety cue, communicates support for stigmatized identities and generates important implications for enhancing outcomes among stigmatized groups, such as 
heightened belonging, performance, trust, and engagement (see Cipollina \& Sanchez, 2019). Specifically, identity safety cues refer to aspects of an environment or setting that signal to stigmatized groups that the threat of discrimination is limited and their social identities are welcomed and valued (e.g., Chaney \& Sanchez, 2018; Cipollina \& Sanchez, 2020; Davies et al., 2005; Emerson \& Murphy, 2014; Johnson et al., 2019; Murphy et al., 2007; Pietri et al., 2018; Purdie-Vaughns et al., 2008; Wout et al., 2014). Identity safety cues can be intentionally constructed or naturally occurring, subtle or explicit, and hold particular promise for improving stigmatized groups' outcomes in threatening domains (e.g., Cheryan et al., 2009; Cheryan, Meltzoff, et al., 2011; Cipollina \& Sanchez, 2020; Davies et al., 2005; Johnson et al., 2019; Pietri, Drawbaugh, et al., 2019). For example, Cipollina and Sanchez (2019) provide a compelling case for using identity safety cues in medical contexts to improve relations between providers and patients and to reduce the negative effects of threat for stigmatized groups in healthcare settings.

If individuals or organizations aim to make environments welcoming, affirming, and nonthreatening, they require an understanding of which identity safety cues exist and which strategies work most effectively. Evidence supporting the ways in which various types of situational cues trigger identity safety is scattered and lacks conceptual organization. We therefore provide a centralized review for not only organizing the identity safety cue literature but determining which efforts generate desired outcomes related to identity safety. We develop a novel taxonomy of identity safety cues, which can serve as a useful analytic tool through which to interpret current literature and frame future research (Ereshefsky, 2000; for example, see Ellemers et al., 2002). A significant contribution of this taxonomy is that it outlines specific types of identity safety cues, their operationalization, and the conditions under which they are most effective. The purpose of this article is thus twofold: (a) to review scientific literature to develop a taxonomy that reflects how identity safety cues are defined and operationalized, and (b) to translate the results of the review to assist efforts of building inclusive environments. We 
review and translate the science with the goal of increasing identity safety among members of stigmatized groups, and we focus on identity safety cues in the context of value threats (i.e., the undermining of a social group's value).

We posit that researchers and policymakers have much to gain from revisiting the scientific literature through the lens of identity safety. Though the research about safety cues complements and often overlaps with that of social identity threat, a review from a different vantage point—one focused on safety—could offer a unique focus on solutions (safety) rather than focusing on social problems (threat). In this article, we review the content of identity safety cues, their strengths and limitations, and implications for future theory, research, and policy. We briefly summarize identity safety cues through their connection to social identity threat and delineate their function. We then present the results of a review of the literature on identity safety cues. Drawing from the literature, we propose a working taxonomy of identity safety cues that target stigmatized groups, namely those minoritized by gender and race. In doing so, we explain the thematic categorization of identity safety cues and the ways in which cues influence stigmatized groups' well-being in various contexts (e.g., education). We identify contradictions in the literature and critically contemplate the strengths and limitations of particular cues. Finally, we conclude with a forward-thinking discussion of theoretical implications and broader impacts, focusing on the lack of intersectionality theorizing in identity safety cue research and the translation of identity safety cue research.

\section{Emergence of Identity Safety Cue Research}

As they navigate intergroup contexts and interactions, members of stigmatized groups attend to information about the potential for bias versus safety (Kaiser et al., 2006; Oyserman et al., 2007; Pachankis, 2007; Richeson \& Shelton, 2007; Steele et al., 2002; Vorauer, 2006). In particular, they take note of information that signals the extent to which a situation will be threatening or affirming (i.e., situational cues) as a function of their group membership. Social identity theory provides a framework for understanding the interaction between individuals and 
situational cues, specifically regarding the consequences of monitoring threat and safety (Emerson \& Murphy, 2014; Inzlicht et al., 2011; Steele, 1997, 2010).

Social identity threat occurs in situations in which people become aware that their social identities can be ascribed undesirable characteristics or that one's preferred sense of their social group is not reflected by how others perceive their social identity (see Branscombe et al., 1999; Ellemers et al., 2002; Major \& Schmader, 2018). Social identity theory accommodates several classes of identity threat, including categorization threat, distinctiveness threat, value threat, acceptance threat, and legitimacy threat (Branscombe et al., 1999; Maass et al., 2003). These threats operate in myriad forms, influence individuals differently, apply to various contexts, and evoke different motivational states and coping strategies (Aronson \& McGlone, 2009; Branscombe et al., 1999; Ellemers et al., 2002; Major \& Schmader, 2018; Steele et al., 2002). Of most importance to the present conceptualization of identity safety are the threats to the value of one's social identity; Indeed, the literature on identity safety cues largely attends to how identity cues impact stigmatized groups in the context of value-based threats (Cipollina \& Sanchez, 2020; Davies et al., 2005). Such value-based threats undermine the strengths and performance of a group and implies the group is inferior to others. Among stigmatized groups in particular, value-based threats occur based on a range of social identities, including gender (e.g., Townsend et al., 2011), race (e.g., Emerson \& Murphy, 2014), sexual orientation (e.g., Fingerhut \& Abdou, 2017), religious identity (e.g., Mackey et al., 2020), social class (e.g., Sandstrom et al., 2019), and weight and body size (e.g., Hunger et al., 2015). This review focuses on identity safety cues as they influence stigmatized groups' psychological processes, though various types of social identity threats can occur among dominant groups as well (e.g., Maass et al., 2003; Scheepers et al., 2009).

Identity safety cues, as evidenced by the findings of this review, are often understood in the context of stereotype-based threat among members of stigmatized groups (Aronson \& McGlone, 2009; Steele, 2010; Steele \& Aronson, 1995; Steele et al., 2002). In formative 
stereotype threat studies, researchers reminded Black students of racial stereotypes about academic achievement. Threatened Black students underperformed on an exam when exposed to threatening pre-test information (Steele \& Aronson, 1995)—revealing how situational cues trigger threat and concomitant negative outcomes. Nearly three decades worth of social psychological research informs our understanding of stereotype-based threat cues, primarily focused on Black students and race-unspecified women in evaluative contexts (e.g., Aronson \& McGlone, 2009; Murphy et al., 2007; Pennington et al., 2016; Spencer et al., 1999, 2016; Steele, 1997; Steele et al., 2002). This vast literature asserts that threat is "in the air" and detected, and contributes to stigmatized groups' negative outcomes in education, work, and health contexts (Emerson \& Murphy, 2014; Major et al., 2013; Steele, 1997, 2010; Townsend et al., 2011). It is thus evident from the social identity threat literature that stigmatized groups are conscious of and vigilant to their potential treatment in situations they encounter: They express concerns about whether they will face rejection and discrimination (Mendoza-Denton et al., 2002; Pinel, 1999; Vorauer, 2006) or whether they will belong and be respected (Bergsieker et al., 2010; Walton \& Cohen, 2007). Although people are more likely to attend to threatening cues than neutral stimuli, they also display attentional bias to safety cues (Schmidt et al., 2017). Individuals are observant of both threat and safety information, suggesting that identity safety cues would be a promising path toward lessening identity threat and enhancing psychological well-being for stigmatized groups.

A significant implication of identity safety cues is that they may assuage feelings of threat even in the context of threatening situational cues, thereby providing a potential solution to the problems posed by social identity threat and addressing a primary goal of social inclusion efforts: to remove threat from situations and enhance inclusion. That is, identity safety cues 'remove the 'threat in the air,' enabling stigmatized individuals to enter previously threatening situations without the risk of being personally reduced to a negative stereotype targeting their social identity" (Davies et al., 2005, p. 278). For example, when negative stereotypes about 
women are activated, Davies and colleagues (2005) found that providing identity-safe information about gender (i.e., assertions that there are no gender-based differences in ability) restored women's leadership aspirations in a potentially threatening task. A similar alleviating effect occurred in the domain of mathematics-women performed better on a math exam after reviewing evidence of other women's accomplishments (Mclntyre et al., 2003). Identity safety cues can also elicit belonging (e.g., Johnson et al., 2019; Murphy et al., 2007). Even in relatively low-stakes environments like on social media, a symbol of support for a stigmatized group can enhance perceived belonging (Matsick et al., 2020). Though some identity safety cues may be initiated by well-intentioned individuals or organizations (e.g., as deliberate effort or intervention; Albuja et al., 2019; Howansky et al., 2021), other cues are more naturally occurring and spontaneous (e.g., demographic ratios of workplaces; Murphy et al., 2007; Purdie-Vaughns et al., 2008). Some identity safety cues are explicit, such as information countering gender stereotypes (e.g., Davies et al., 2005; Mclntyre et al., 2003); whereas other cues are relatively implied, such as subtle characteristics of situations (e.g., a poster on a wall or language used in demographic questionnaires; Cheryan et al., 2009; Matsick et al., under review). We thus infer that identity safety cues encompass a diverse set of situational cues (e.g., information, visible features, verbal and non-verbal signals) and that they reduce threat, enhance psychological outcomes, and communicate a commitment to social inclusion and diversity.

In the current research, we conducted a wide search of the scientific literature in 2019 , 2020 , and 2021 to build a taxonomy of identity safety cues and a critical understanding of their value. Taxonomy, a widely used framework in the biological sciences, serves as a classification system that offers universal naming (language) and descriptions (definitions) of identified categories (Ereshefsky, 2000). Taxonomies are fundamental for developing coherent literatures by organizing large and varied sources of information into a more unified and defined classification. Within psychology, taxonomies exist for conceptualizing a range of operationalizations and constructs, such as microaggressions, personality characteristics, 
situations, social identity threats, and wellness strategies (Branscombe et al., 1999; Ellemers et al., 2002; Frederiksen, 1972; John, 1989; Nadal et al., 2016; Nash et al., 2013; Sue et al., 2007) - each providing helpful nomenclature, structure, and operational definitions for building the science in the respective area. A taxonomy of identity safety cues can likewise facilitate clear and universal communication about the science, delineate types of operational definitions, and direct future research and theorizing.

\section{Method}

In reporting methodological procedures, we follow the recommended format from PRISMA (Page et al., 2021), except where not applicable (e.g., guidelines for reporting metaanalytical statistics).

\section{Inclusion and Exclusion Criteria}

We established inclusion criteria to identify empirical articles that operationalized an identity safety cue (i.e., an aspect of the environment or social setting that communicated one's identity is valued and that discrimination is unlikely). Our exclusion criteria applied to articles that focused on threat cues exclusively, theoretical or review articles, dissertations and theses, or cues that were not specific to identity safety (e.g., feeling safe from the possibility of electric shock; Engelhard et al., 2015). Complications with our inclusion and exclusion criteria stemmed from conceptual overlap between identity threat and safety. Many articles contained both threat and safety cues, as they often work as two sides of the same coin in manipulations (e.g., a greater number of Black employees signals safety whereas a low number of Black employees signals threat). In these cases, we included articles if they explicitly mentioned safety. We thus proceeded to tailor our review to articles that included identity safety cues as a central focus, and we excluded articles that solely attended to threat with little discussion of identity safety. We did not limit our search based on methodology, discipline, or year published, though we recognize that this literature is largely from the last two decades. We did not search for effects on specific dependent variables. Instead, the search focused on the use and operationalization 
of identity safety cues. As such, measurable outcomes (e.g., belonging, trust) vary between studies even if the cue operationalization is similar. We did not exclude based on sample characteristics; For example, we did not require samples to represent a specific demographic group (e.g., women).

\section{Article Selection}

We used four specific sources to compile data: PsycINFO, reference lists of relevant articles, relevant authors' publication records, and a manual search via Google Scholar to supplement the search results. For example, when researchers operationalized identity safety cues based on precedent, we tracked prior references and any relevant others from the authors cited. Search terms used on each database included "safety cue," "diversity cue," "safety signal," "identity safety," "threat cue," and "situational cue," among others (see Figure 1). When appropriate, we incorporated research that we found outside of the formal literature review. For example, we added more recent studies that we learned of at the 2021 annual meeting of the Society for Personality and Social Psychology or through publication announcements on social media (i.e., journal or researcher accounts on Twitter). All sources and databases were last searched prior to submission (April 2021) and again in the review process (June 2021).

The first author worked independently to compile articles by reading all abstracts that appeared relevant to the project. An article was downloaded for further review if it met the inclusion criteria and was not downloaded if it met exclusion criteria. After articles were downloaded, the first author independently read each article twice, taking notes on cue operationalization, methods, and results. Any articles that were not relevant upon review were excluded and the reason noted, with the first author consulting with the second author about the selections and justifications. After reviewing the articles, both authors concluded that the use of identity safety cues overwhelmingly focused on gender and race, and that there was enough literature to warrant a gender- and race-specific review. That is, because there is a dearth of research on cues targeting a broader set of social identities (e.g., sexual orientation), whereas 
gender and race were strongly represented in the literature, we made a post-hoc decision to narrow our taxonomy to identity safety cues targeted toward people based on gender and race. Consequently, this taxonomy is not generalizable to all stigmatized social groups at this time. See Figure 1 for a flowchart of the article selection process.

In sum, we identified 38 articles to review in building a taxonomy (Table 1). We assert that this review is conceptually comprehensive, such that the reviewed literature eventually reached saturation in developing a taxonomy, but we acknowledge that the review may not be exhaustive and inclusive of all relevant scholarship.

\section{Coding Procedure}

The note-taking process during article selection provided a useful starting point for coding, as we had compiled a list of all identity safety cue operationalizations observed in the literature. Using this list and revisiting articles, the first author then identified larger themes and overlap among the different cue operationalizations. For example, the first author noted that multiple articles operationalized an identity safety cue through the presence of other stigmatized individuals, which eventually led to the category of Minority Representation. This initial theme generation process led to nine themes, which were then refined into six. Next, the first author met with the second author to present the themes while providing definitions and example studies. Through collaboration and reexamining articles together, the first and second authors collapsed across themes to describe the data more concisely and to extract patterns and important insights (as in Braun \& Clarke, 2006). The themes were then used to develop four types of categories, which had clear definitions to be used for coding the content of each article.

The first author coded the 38 selected articles to indicate whether each of the four cue types were present or absent in an article. With a binary yes/no code, the first author also coded whether each article used an identity safety cue to target race exclusively, gender exclusively, or both race and gender. As some articles contained more than one type of cue, articles could be coded into multiple categories of the taxonomy. To account for bias, we also employed a 
dual-coding scheme. Consistent with content analysis guidelines (O'Connor \& Joffe, 2020), the second author independently coded a random $20 \%$ of the articles. Interrater reliability, assessed by Cohen's $\kappa$, ranged from .71 to 1.00 (all $p$-values $<.05$ ), demonstrating strong agreement between coders. Disagreements were straightforward to resolve (e.g., typographical errors in coding), and were settled by the two authors negotiating to reach consensus about which code(s) should be applied.

\section{Results: Taxonomy of Identity Safety Cues}

We present four categories of identity safety cues and summarize key findings within each area that illuminate operational definitions and uses of identity safety cues. See Table 1 for an overview.

In terms of what has been studied, the outcomes (i.e., dependent variables) in the identity safety cue literature varied, suggesting that identity safety is a multi-faceted and complex experience that can span feelings, attitudes, and behaviors. Across the findings, identity safety cues were expected to increase positive psychological outcomes (e.g., belonging, interest, trust, performance) and decrease negative psychological outcomes (e.g., stereotype threat concerns, anticipated bias and stigma). Identity safety's breadth in definition is both a strength and limitation to the current review. As a strength, it invites an expansive understanding of a range of positive experiences among stigmatized groups; As a weakness, it makes it difficult to organize findings around a clear and definitive outcome. The taxonomy is thus organized by the operationalization of identity safety cues rather than specific consequences or outcomes of identity safety cues.

In terms of who has been studied, the research on identity safety cues prioritized stigmatized groups' responses to cues. Though members of dominant groups may have been part of the design and sampling strategies in studies, the literature collectively emphasized and centered stigmatized groups in understanding the impact of identity safety cues—often indicating that dominant groups were unaffected by cues that targeted stigmatized groups. We 
revisit the effects on dominant groups in the discussion. Specifically, the cues targeted identity safety for people minoritized by their gender or race. That is, the identity safety cue literature mostly focused on how safety emerged among race-unspecified women (though often drawing upon samples of mostly White women) and people of color (though often drawing upon samples of Black/African American women and men). Other devalued social identities, such as in the domain of sexual orientation, ability, socioeconomic status, or nationality, were underrepresented in the study of identity safety cues. In the screening process, we found two articles that focused on sexual orientation (Cipollina \& Sanchez, 2021; Matsick et al., 2020) and one article that focused on socioeconomic status (Browman \& Destin, 2016), but they were excluded because of our post-hoc decision to narrow the focus to gender and race. Together, approximately $24 \%$ of articles targeted race, $47 \%$ targeted gender, and $29 \%$ targeted both race and gender.

\section{Cue 1: Minority Representation}

Minority representation describes manipulating the presence of a stigmatized group to evoke feelings of safety in other members of stigmatized groups. The evidence for minority representation as an identity safety cue is robust, and emerged from laboratory-based experiments, daily diary studies, and manipulations of fictional organization's recruitment materials. Many of the studies focused on male-dominated and predominantly White settings (e.g., STEM contexts) that would be threatening for women and racial minorities, respectively. These identity safety cues appeared in various ways: visually depicting stigmatized groups in advertising, informational, or website materials (e.g., photographs, videos); describing the proportion of stigmatized groups in a setting (e.g., graphs, descriptive information); and highlighting the presence of stigmatized groups as role models or higher status figures within an organization. Approximately $44 \%$ of research on minority representation targeted race, $31 \%$ targeted gender, and $25 \%$ targeted both race and gender. 
The science supports the basic premise of minority representation: The mere presence of one's stigmatized group facilitates identity safety (e.g., Lee \& Park, 2011; Murphy et al., 2007; Wout et al., 2010). As one test of minority representation as a (gendered) safety cue, women who viewed gender-balanced representation within a fictional STEM workforce (i.e., safety cue) experienced less vigilance, a higher sense of belonging, and a greater desire to participate in the organization's events than did women who reviewed a male-majority workforce (Murphy et al., 2007). Also, within STEM, being exposed to a female role model can alleviate the identity threat women experience after learning of gender bias in STEM (Pietri, Hennes, et al., 2019). Similar cue effects transpired beyond STEM contexts too. Black participants expected to be perceived more fairly by a White interaction partner when knowing that the White person's friend network had Black people represented (Wout et al., 2010), although later studies revealed that the ways in which the White person treated their friends (e.g., only engaging in stereotypically Black activities with Black friends) undermined the safety caused by minority representation (Wout et al., 2014). In a study of medical spaces, Black and Latinx participants reported greater anticipated comfort and treatment with a new physician when the physician had racially-diverse clientele (Cipollina \& Sanchez, 2020). Using a virtual world paradigm (Second Life), racial minority women and men felt less belonging, less intention to participate, and less freedom in designing their characters when playing with all White avatars versus a mixture of White and racial minority avatars (Lee \& Park, 2011). Together, findings indicated that stigmatized groups derive safety from the presence of similar others.

Pairing minority representation with diversity policies, Purdie-Vaughns et al. (2008) found that greater numeric representation of African American workers in a fictional company, via pictures of the workforce in a brochure, caused African American participants to feel more trust. Numeric representation cued identity safety regardless of whether the organization described diversity as part of company's values. Likewise, when viewing a hypothetical workplace with more Black employees compared to a workforce with less racial/ethnic diversity, 
Black women and men expressed greater organizational fit, workplace authenticity, and performance, as well as lower perceptions of diversity dishonesty (i.e., the extent to which a workplace lies about its diversity; Wilton et al., 2020). In Purdie-Vaughns et al. (2008) and Wilton et al. (2020), the representation of Black/African American people superseded statements about dedication to diversity—suggesting that a "show, don't just tell" approach bears the greatest identity safety.

The content of minority representation (e.g., role, position of power) also mattered. People with authority served as identity safety cues when exhibiting minority representation. For example, Black students performed better on a diagnostic test when they had a Black evaluator than a White evaluator (Wout et al., 2009), an effect explained by Black students' decreased perception that they would be stereotyped by the Black evaluator. The presence of an ingroup member in the evaluator position provided some degree of safety. Minority role models similarly served as identity safety cues. Drawing from the Stereotype Inoculation Model (Dasgupta, 2011), contact with successful ingroup members inoculates individuals from self-doubt. Latina women felt greater trust, belonging, and interest in a fictional STEM company when viewing a Latino/a scientist employee than a White woman/man scientist (Pietri, Drawbaugh, et al., 2019), and Black women students with a Black STEM professor anticipated greater belonging and trust than students without a Black STEM professor (Johnson et al., 2019). However, for Black women students with high stigma consciousness (i.e., chronic knowledge of societal discrimination against Black women; Pinel, 1999), only the Black woman STEM professor instilled identity safety. That is, in terms of belonging and trust, Black women with high levels of stigma consciousness were best served by role models who matched them in both gender and race. Pietri and colleagues (2018) discovered a similar effect: Black women with high stigma consciousness experienced greater trust and belonging when exposed to a Black woman scientist than a Black man scientist on a STEM company's website (Pietri et al., 2018). Taken together, individuals high in stigma consciousness may require specific forms of minority 
representation and role models (e.g., targeting the intersection of Black women's experiences as women and Black).

Finally, an emerging body of research within the identity safety cues literature indicated that minority representation for one stigmatized group can prompt identity safety among a different stigmatized group. Chaney et al. (2018) found that the presence of a Black man, compared to a White or Asian man, caused less concern about gender stereotypes among White women and greater working memory performance on a task. Given that White women and Black men share underlying stereotype content of lacking intelligence (i.e., both stereotyped as incompetent; Chaney et al., 2018; Wout et al., 2009), the potential effect that minority representation can have on another minoritized group may depend on whether social groups share similar stereotype content (Cipollina \& Sanchez, 2019).

\section{Cue 2: Diversity Philosophies and Programming}

The literature provides mixed evidence about the extent to which diversity policies, or an individual's or organization's claims of diversity values, cause identity safety. Researchers often manipulated information about diversity philosophies in experimental, laboratory-based studies using written information on hypothetical organizations' mission statements, advertising materials, and websites. These cues emphasized a commitment to valuing inclusivity, differences, and multiculturism, which often contrasted with colorblind ideology (i.e., beliefs that people's social identities do not matter) or the absence of any diversity messaging altogether. Approximately $31 \%$ of research on diversity philosophies and programming targeted race, $38 \%$ targeted gender, and $31 \%$ targeted both race and gender.

As reviewed previously, Purdie-Vaughns et al. (2008) and Wilton et al. (2020) combined the content of diversity statements with minority representation in a series of laboratory-based experiments. Though minority representation increased African American participants' trust for an organization regardless of the organization's diversity policy, the content of the diversity statement cued safety when minority representation was low (Purdie-Vaughns et al., 2008). In 
other words, when the organization lacked representation of the stigmatized ingroup (i.e., other African Americans), African American participants trusted the company more when its statement emphasized diversity than when its statement conveyed a colorblind ideology. Similar effects of colorblind ideologies were found by Wilton et al. (2015), where women of color performed worse on a math test after reading about an organization's colorblind ideology. In contrast, Wilton et al. (2020) found that organizations' statements (a neutral statement versus diversity statement in a technology company's brochure) did not influence Black/African American participants' perceptions of organizational fit, authenticity, performance, or diversity dishonesty-leading Wilton et al. (2020) to conclude that minority representation works more efficiently than diversity philosophies. Similarly, Cipollina and Sanchez (2020) found that physicians' diversity statements did not influence Black and Latinx participants' anticipated quality of the first visit. In contrast, a daily diary paradigm revealed that gender-inclusive workplace policies related to women engineers' (actual and expected) greater feelings of acceptance, more positive interactions with male colleagues, and less social identity threat (Hall et al., 2018). Whereas the organization's diversity philosophy predicted women's identity safety, the number of women in a workplace (minority representation) did not.

Extending research on diversity philosophies, individuals' and organizations' beliefs about intelligence signaled identity safety. When a consulting company displayed an incremental theory of intelligence (i.e., beliefs that intelligence and abilities are malleable) through their mission statement or website, compared to an entity theory of intelligence (i.e., beliefs in the fixed nature of intelligence), women trusted the company more (Emerson \& Murphy, 2015). Women also expected to be less stereotyped in the company with the incremental theory of intelligence compared to the company with an entity theory (Emerson \& Murphy, 2015). Gender representation within the company did not affect women's trust in the company, echoing Hall et al.'s (2018) findings that, at least in the context of gender, companywide philosophies may have more impact than minority representation. 
Beyond workplace domains, diversity philosophies cued safety among students in higher education too. Professors' theories of intelligence (i.e., believing that intelligence is fixed or malleable) impacts students' psychological outcomes, such that professors holding a malleable theory of intelligence promoted greater belonging in students (Muenks et al., 2020). Including a diversity philosophy (versus colorblind messaging) in chemistry, math, and physics classes fostered more belonging, greater quiz performance, and less perceived instructor bias among students of color (Good et al., 2020). Similarly, an instructor's non-discrimination and equity policy led undergraduate students in a social psychology course to report greater perceived inclusivity, more belonging, fewer course absences, and greater expectations for fair treatment by the instructor than when identity safety cues were omitted (Howansky et al., 2021). However, Howansky and colleagues' (2021) quasi-experimental design simultaneously used many cues (e.g., diversity statements, symbols, pronouns); therefore, the extent to which diversity philosophies alone contributed to safety is unclear.

Finally, similar to the transfer effect for minority representation, diversity philosophies aimed at one stigmatized group induced identity safety in another stigmatized group. White women felt greater identity safety when presented with a company with organizational diversity structures (e.g., diversity trainings, awards and recognitions for diversity) explicitly aimed at racial minorities compared to a control; Similarly, men of color felt greater identity safety when a company had organizational diversity structures explicitly aimed at women compared to a control (Chaney et al., 2016). As another example, a statement of inclusivity regarding sexual and gender diversity on a fitness gym's brochure led to greater intentions among (presumably heterosexual) women to join the gym than when the gym's advertising materials lacked sexual and gender diversity information (Cunningham \& Melton, 2014). In addition to the transfer effect, some evidence suggested that the most promising diversity initiatives should be aimed at all employees (e.g., not only women employees) and organized by a collective (e.g., not only by 
management) in order to work effectively (Cundiff et al., 2018). Taken together, diversity philosophies that are far-reaching may cue safety for multiple stigmatized groups.

\section{Cue 3: Environmental Features}

Sometimes referred to as "ambient cues" (Cheryan et al., 2009), environmental cues include features of one's surroundings that induce identity safety by communicating the norms and values of a setting. These cues require people to look around and interpret the stereotypes or lack thereof that are broadcasted by a context's physical characteristics. Environmental cues often pair with minority representation and diversity philosophies (e.g., a fitness gym's use of a diversity statement and visible rainbow pride symbol; Cunningham \& Melton, 2014). Research has included an array of environmental cues (e.g., posters on a wall, items on a table, nearby knickknacks) that together improve safety (e.g., belonging, interest) for stigmatized groups in that setting. Such studies involved experiments that manipulated descriptions of the environment, real settings, and virtual environments across a number of domains (e.g., classrooms, doctor's offices, workplaces). Though these cues are numerous and diverse, they share an underlying purpose: to limit stereotypical images in the environment and to disseminate more inclusive messaging about who belongs. Approximately $11 \%$ of research on environmental features targeted race, $67 \%$ targeted gender, and $22 \%$ targeted both race and gender.

The creation of gender-neutral spaces strengthened women's identity safety. Female students' interest in STEM increased when researchers embedded non-stereotypical, neutral items (e.g., nature poster) in a computer science environment compared to stereotypically masculine items (e.g., Star Trek poster; Cheryan et al., 2009). To hold numeric representation constant, the researchers gave participants the choice of joining one of two teams in different environments, but both teams were entirely comprised of women. Even in all-women conditions, female students were more likely to choose the non-stereotypical environment over the stereotypical one. Likewise, using a virtual classroom paradigm via Second Life, women 
expressed greater interest, belonging, and anticipated success in a computer science classroom when viewing non-stereotypical features of the classroom (e.g., magazines, plants) than stereotypically masculine ones (e.g., science fiction books, video games; Cheryan, Meltzoff, et al., 2011). Environmental cues also affected actual performance. Latu and colleagues (2013) used immersive virtual environment technology to subtlety expose women and men to a nearby image of a leader (e.g., Bill Clinton, Hillary Clinton, Angela Merkel) or no image. In a virtual room, participants engaged in a public speaking task with an audience and poster on the opposite wall. When exposed to a poster of Bill Clinton or no poster during a public speaking task, women spoke significantly less than men; however, when exposed to Hillary Clinton or Angela Merkel, the gendered gap in speaking time was significantly narrowed. Implanting a high-status female role model or images of like others in the environment bettered women's actual performance (for another design in a science setting, see Good et al., 2010). Environmental cues communicated norms beyond STEM spaces. Prenatal doctor's offices with father-friendly cues (i.e., pictures of fathers with babies) contributed to expectant fathers' identity safety (Albuja et al., 2019). The father-friendly environment, compared to a control condition that targeted mothers and infants, increased expectant fathers' comfort with attending prenatal appointments, for example. In a series of experiments using digital mockups of an office space, Chaney and Sanchez (2018) found that when an organization included a gender-inclusive bathroom, in contrast to bathrooms designated by sex, cisgender women perceived the organization as less gender-essentialist and consequently felt more identity safety (e.g., anticipated less gender-based stigma and greater fairness). The effect also held for racial minority men: They anticipated less race-based stigma. Building design, such as structural features that represent racist histories, also influenced stigmatized groups' wellbeing. Driskell and Trawalter (2021) found that Black participants felt greater belonging when exposed to buildings with New American architecture as compared to Antebellum architecture (i.e., historical pre-Civil War architecture). Overall, environmental cues triggered identity safety and 
diminished stereotypes about various contexts, which promoted comfort, interest, and expectations for being treated fairly.

\section{Cue 4: Identity-Safe Information}

The final cue category involves providing members of stigmatized groups with explicitly non-threatening information that induces identity safety. This cue most often occurred in evaluative contexts (e.g., testing situations, academia). The potential threat involved with certain contexts or intergroup interactions can be lessened through explicitly stated identity-safe information that limited the importance or relevance of negative stereotypes, emphasized previous markers of performance, and conveyed fair and positive expectations. Approximately $0 \%$ of research on identity-safe information targeted race, $55 \%$ targeted gender, and $45 \%$ targeted both race and gender.

As one example of limiting the relevance of negative stereotypes, Wout et al. (2009; which falls into the race and gender category) found that describing a test as non-diagnostic of intellectual ability, compared to describing it as diagnostic, served as an identity safety cue for Black students because they encountered less risk of confirming negative stereotypes about their competency and intelligence. Whereas differences in test performance existed between Black students with White evaluators and Black students with Black evaluators in the diagnostic testing condition, no such differences existed between students when the testing information revealed that the exam was non-diagnostic of intellect.

Similar effects were demonstrated in the context of gender and domains in which women may be threatened (e.g., mathematics, leadership) because of negative gender stereotypes. Reminding women of other women's accomplishments prior to a math test improved women's test scores and eliminated the gendered gap in performance (Mclntyre et al., 2003), telling women that there are no differences in women's and men's leadership abilities eliminated gendered gaps in leadership aspirations (Davies et al., 2005), and informing women about how other women in STEM thrive despite gender bias partially alleviated the negative effects of 
learning about gender bias in STEM (Pietri, Hennes, et al., 2019). Reframing and lessening the stereotypes associated with masculine domains, such as beliefs about computer science as geeky and anti-feminine (Cheryan et al., 2013; Mercier et al., 2006; Rommes et al., 2007), also strengthened women's identity safety. When female participants read an article that claimed non-stereotypical findings about computer science majors ("Study finds computer science no longer dominated by 'geeks"') versus stereotypical findings ("computer science continues to be dominated by 'geeks'”), women's interest in computer science increased (Cheryan et al., 2013). Similarly, when female participants virtually interacted with a non-stereotypical woman in STEM (i.e., a woman who enjoyed sports and The Office) versus a stereotypical woman in STEM (i.e., a woman who enjoyed video games and Star Wars), women's anticipated success and felt similarity in STEM improved (Cheryan, Siy, et al., 2011). In sum, information that redressed gender stereotypes increased women's interest, belonging, and expected performance in domains once considered to be incongruent with them.

Information about expectations for bias also emerged as an identity safety cue. In various studies, the presence of non-Black women who were racial allies enhanced Black women's belonging (e.g., Johnson \& Pietri, 2020; Johnson et al., 2019; Pietri et al., 2018). In Chaney et al. (2020), women of color evaluated a White male professor who was either described as an ally to women or as neutral. When Black and Latina women reviewed the White male professor who was an ally to women, they experienced greater gender identity safety and racial identity safety than in the neutral condition. That is, women of color felt dual identity safety (i.e., by gender and race) when exposed to safety-inducing information about only one identity (i.e., gender). This area of cue research identified the potential for double safety cues (Chaney et al., 2020), such that people with multiple stigmatized identities (Black women) may experience dual identity safety from a single identity cue (e.g., gender cue).

\section{General Discussion}


Broadly speaking, individuals and organizations aim to know which strategies toward greater inclusion and diversity make best use of their resources. We proposed that identity safety cues are one tactic, and the evidence overwhelmingly supported our claim while revealing some caveats and boundaries to cue efficacy. This review thus identified relevant literature, synthesized scientific findings, and organized the research into four categories of cues that target gender and race. Given the strong foundation of research on identity safety cues and the desire among individuals and organizations to create environments that welcome stigmatized groups, we identify safety cues as a promising avenue for both research and policy. We encourage researchers to integrate intersectionality theory while building the identity safety literature, and we advocate for implementing identity safety cues that are evidence-based and wield transformative potential. As noted by Grzanka et al. (2020), "an intersectional approach to scientific inquiry would put translation at the conceptual center" (p. 306). We thus draw heavily from the tradition of intersectionality to imagine the theoretical and practical future of identity safety cues.

\section{Intersectional Theorizing}

Limited by single-axis characteristics, identity safety cues in previous research often did not account for the reality of social groups' experiences of holding multiple identities. We reiterate the call that future research in psychology take intersectionality seriously (Grzanka, 2018; Grzanka et al., 2020; McCormick-Huhn et al., 2019; Settles et al., 2020). Emerging from Black feminist thought to center Black women's interrelated experiences of racism, sexism, and classism (Collins, 2000; Crenshaw, 1989, 1991; hooks, 1984), intersectional perspectives provide a lens through which psychological researchers can appreciate within-group differences (e.g., within the category of "women") and the situated nature of identities within broader structures (e.g., sociopolitical and historical contexts; Cole, 2009; Warner, 2008). Intersectionality theory emphasizes that (a) individuals occupy distinct positions of systematic advantage and disadvantage as a function of their unique constellation of identities (e.g., 
Purdie-Vaughns \& Eibach, 2008), (b) systems of oppression are multiplicative and interlocking - producing experiences not captured by sexism or racism alone (e.g., Bowleg, 2008), (c) social change necessitates knowledge of intersectionality and accompanying power dynamics (e.g., Overstreet et al., 2020), and (d) the act of applying an intersectional lens in research and practice must not be depoliticized (e.g., Buchanan \& Wiklund, 2021). By applying intersectional perspectives, researchers will better address the transformative potential of cues.

Gender and race emerged as the primary targets of situational cues in this review; Yet, in a lot of cases, the research lacked a thorough analysis of the interconnectedness between the two identities (gender, race) and experiences of stigma (sexism, racism). There were noteworthy exceptions that contended with people's multiple identities simultaneously (Chaney et al., 2020; Johnson et al., 2019; Pietri, Drawbaugh, et al., 2019; Pietri et al., 2018). These studies often highlighted the need for intersectional specificity in evaluating cue efficacy. Johnson and colleagues (2019) demonstrated the practical import of not only studying role models (minority representation), but also considering which role models elevated identity safety among Black women. That is, gender-based cues alone will be insufficient for women of color sometimes. However, in other cases, it is possible for people who are stigmatized by gender and race (e.g., Black women) to feel both gender-based safety and race-based safety from a gender-based display of allyship (cue 4: identity-safe information; Chaney et al., 2020)—a double safety cue. At the most basic level, an intersectional lens would suggest that different groups benefit differently from the same cue depending on the broader context and power dynamics surrounding the situation, and that the same group may benefit differently from a cue depending on the surrounding context. Thus, for cues to succeed, they should be tested for targeting intersectional positionality and for yielding double functions. Interventions for promoting diversity and social inclusion require recognition that people do not hold single-axis identities (Overstreet et al., 2020). Therefore, regardless of which type of cue is implemented, an intervention that employs single-axis cues to instill identity safety may not always address 
the needs of people who encounter multiple forms of stigma. We recommend researchers look within race as a social category or look within gender for critical information to evaluate for whom cues are effective.

At the heart of intersectional theorizing is recognition of power. A strength of using identity safety cues toward social inclusion and diversity is that they place responsibility on highpower entities (e.g., members of dominant groups, institutions, organizations) to change a situation instead of requiring low-power individuals to cope with or change themselves to fit an existing context. For example, creating diversity philosophies, designing features of the environment, and recruiting and retaining members of stigmatized groups serve to signal safety and require deliberate effort from those with power. We propose that radical cue implementation can counteract sociopolitical and historical inequities by reestablishing who is (un)fit, (un)welcomed, and (de)valued in various contexts. Cues should be endorsed by those with power and should convey a willingness to redistribute power (i.e., by signaling new possibilities for who belongs). In doing so, cue use may require people to resist the urge to depoliticize themselves and their environments (e.g., schools, workplaces, healthcare). That is, some identity safety cues might be read as activism and confrontation politics (e.g., Black Lives Matter sign, rainbow flags; Matsick et al., 2020; Rickford, 2016), and this may interfere with people's beliefs that places of learning, work, and health are apolitical. However, feminist philosophers and sociologists assert that experiences of everyday life are never apolitical for those who are oppressed and lacking power (Harding, 2004; Smith, 1987). We therefore suggest that efforts to avoid "politics" may be incompatible with what identity safety cues must do: make a (politicized) statement.

Finally, though intersectionality theory best centers the lived experiences of Black women, some tenets of intersectionality theory may be useful for broadening the application of identity safety cues in recognition of who has been left out of previous research and which power dynamics remain unaddressed. As noted, every reviewed article focused on signaling 
safety by gender or race. This pattern is unsurprising given identity safety cue research emerged from foundational studies based on gender and race in the stereotype threat literature. Nevertheless, people who encounter stigma based on other identities, such as sexual orientation, social class, and weight, display vigilance to their environments and navigate spaces keenly aware of situational cues that influence their belonging (e.g., Cipollina \& Sanchez, 2021; Matsick et al., 2020; Oswald et al., under review; Trawalter et al., 2021). The neglect of people's identities beyond gender and race constrains the applicability of identity safety cues and leaves behind vulnerable populations as individuals and organizations plan to transform their environments. As noted throughout the review, growing evidence exists to suggest that some cues provide wide-reaching properties. The stigma-by-prejudice transfer effect describes when a member of a stigmatized group feels increased threat or safety from a cue directed at another stigmatized group (Sanchez et al., 2017, 2018). As one example, cisgender women felt greater identity safety in a workplace with gender-inclusive bathrooms, a measure ostensibly meant to signal safety to transgender and gender non-conforming people (Chaney \& Sanchez, 2018). For identity safety cues to reach their full potential for transforming spaces, policymakers should advocate for multifunctional cues (i.e., cues that transfer) and future researchers should test a more encompassing catalogue of identity safety cues to address lived experiences beyond gender and race.

\section{Translation of Identity Safety Cues Research and Broader Impacts}

Identity safety cues may appeal to those seeking to enhance social inclusion and promote diversity because they are relatively easy to implement and can be cost-effective. Most importantly, as shown by this review, identity safety cues are evidence-based. Sound intervention necessitates scientific evidence but the literature is often lacking. Among more than 2,000 articles about campus diversity initiatives, less than $2 \%$ evaluated the efficacy of diversityfocused efforts (Patton et al., 2019). Our review supports the usefulness of identity safety cues, though we recognize the possible overrepresentation of studies showing significant results (cue 
effects) than studies with non-significant results (a lack of cue effects) because of systematic publication bias in favor of significant, positive, and exciting findings (see Nosek et al., 2012). Nevertheless, while we promote the use of identity safety cues, we critically reflect on the literature to theorize about boundaries of cues and recommendations for best practices for cue implementation.

\section{Under Which Conditions Do Cues Work Best?}

Identity safety cues have boundaries and conditions under which they most effectively operate. The stereotype threat literature indicates that the extent to which a situational cue is legible and efficacious depends on the individual, the cue and its saliency, and the environment (Kaiser et al., 2006). We propose that those seeking to instill identity safety may find the same considerations useful for the translational success of identity safety cues.

The Individual. People's attention to stigma plays a significant role in cue efficacy. First, stigma consciousness refers to individual differences in people's expectations for encountering stereotypes (Pinel, 1999). Different levels of awareness of stigma contribute to how cues induce safety; Black women students with high stigma consciousness only felt increased safety from the presence of Black women professors (not Black men professors; Johnson et al., 2019). Second, stigma solidarity—an individual's belief that oppressed people should work together to pursue equality -influences the effect of cues. White women with high stigma solidarity perceived a Black man as less sexist than a White man due to their beliefs that marginalized groups should "stick together" (Chaney et al., 2018). Third, endorsing monolithic prejudice (i.e., the extent to which an individual perceives other people's bias toward one stigmatized group as reflecting their bias toward other stigmatized groups) explains how cues impact non-targeted groups (stigma-by-prejudice transfer; Sanchez et al., 2017, 2018). Given this effect and corresponding literature regarding the transfer of identity safety cues (e.g., Chaney \& Sanchez, 2018; Chaney et al., 2016, 2018; Cunningham \& Melton, 2014), beliefs in monolithic prejudice help to explain why feelings of safety occur among one stigmatized group when exposed to 
identity safety cues aimed at another group. Taken together, individuals with high stigma consciousness may require specific cues, and individuals who endorse stigma solidarity and monolithic beliefs about prejudice may be more strongly persuaded by the presence of identity safety cues compared to others.

The Cue. Drawing from the stereotype threat literature, the saliency of a cue may limit its potential for inducing safety. Given that ambiguous threats are most noticed by those high in stigma consciousness (Kaiser et al., 2006), ambiguous identity safety cues may be similarly constrained in their reach, such that those who are less chronically vigilant may overlook or be unaffected by the safety cue. It is likely that real-world situations comprise multiple cues, some of which may support or oppose each other. The notion of multiple cues presents an essential future area of research not only for external validity purposes, but also because multiple cues can influence the saliency and relative importance of each identity safety cue. A safety cue coexisting with another safety cue could neutralize one of the safety cues, the pairing of two safety cues could boost one another, or a safety cue and a threat cue could compete with each other. For example, the presence of a threat cue (e.g., stereotypical beliefs about Black people) can override Black participants' derived safety from minority representation (Wout \& colleagues, 2014). Further, comparing results across safety cue studies, it is evident that more research is needed to determine the effectiveness of diversity philosophies and programming in light of minority representation. In its current form, the literature suggests that for Black/African American individuals minority representation matters more than explicit statements that value diversity (Cipollina \& Sanchez, 2020; Purdie-Vaughns et al., 2008; Wilton et al., 2020); however, for women in a threatening setting (i.e., engineering), an organization's philosophy had a greater effect on safety than the representation of other women (Hall et al., 2018). Despite mixed findings, we draw across results to infer that in the absence of minority representation, diversity statements may be effective for providing safety, but the effects of identity safety can differ when multiple cues are present. 
The Environment. Individuals in prejudiced environments (i.e., prejudice places; Murphy et al., 2018) attend more to cues than those in nonprejudiced environments (Emerson \& Murphy, 2014; Kaiser et al., 2006). While vigilance to their surroundings can be adaptive for stigmatized groups — to evade threat and secure safety—it also psychologically taxes them by placing demand on their attention (Oyserman et al., 2007; Pachankis, 2007), which may detract from their performance in threatening contexts. An environment conveys threat when an individual decides that stereotypes associated with their group membership apply to the immediate setting and broader societal context; therefore, they expect to encounter prejudice and bias (Wout et al., 2009). For example, a Black man may perceive a classroom as threatening if they determine that negative stereotypes about Black men's intellect or competence are pertinent to the immediate setting (i.e., the classroom) and the broader social context (e.g., the type of institution or subject matter). In such a situation, identity safety cues that combat negative stereotypes about Black men's belonging or fit (e.g., minority representation, environmental features) or communicate intentions to treat Black men fairly (e.g., diversity philosophies, identity-safe information) should alleviate threat. If the environment lacks threat, identity safety cues may hold less power because stigmatized groups would not be hypervigilant to the situation and identity safety among stigmatized groups could already be sufficient.

\section{Ethical Considerations}

This article stands as a central source for making sense of the science of identity safety cues. However, as we promote evidence that supports the use of cues, we also caution researchers and policymakers from making haste decisions. Best practices for promoting social inclusion and diversity emphasize the need for progressive initiatives to be met by progressive policy and structural changes (Carter et al., 2020; Onyeador et al., 2021). While identity safety cues can be implemented by well-intentioned individuals and organizations who wish to appear inclusive or raise awareness (e.g., signaling support as allies; Chapman \& Coffé, 2016), they 
can sometimes be used superficially by individuals and organizations in pursuit of their own goals (e.g., partaking in racial capitalism, rainbow capitalism, or performative gestures; Falco \& Gandhi, 2020; Henry, 2016; Leong, 2013). As found in other research, intentions for building inclusion and diversity do not always equate impact (Kaiser et al., 2013; Kalev et al., 2006; Legault et al., 2011; Onyeador et al., 2021); It is therefore important to be mindful and critical of cue use and motivations. Racial capitalism and rainbow capitalism, for example, are processes by which identity safety cues could be harnessed for social and economic value owned by nonstigmatized entities (Falco \& Gandhi, 2020; Leong, 2013). For example, racial capitalism can occur as organizations exploit, rather than support, the presence of stigmatized groups (i.e., minority representation), and rainbow capitalism can occur as diversity symbols become commodified (i.e., environmental features) to enhance the social status and value of the cue implementer. Such practices are problematic because they deprioritize the benefits of safety cues for stigmatized groups and instead shift the focus to what cue implementers can gain. As a result, the use of a cue like racial minority representation, such as in universities' advertising materials (Roediger, 2005 as cited in Cipollina \& Sanchez, 2019), can be met with criticism and suspicion, as can the superficial and appropriated use of rainbow pride diversity-related symbols-a phenomenon often occurring during Pride month called "rainbow washing" (Bitterman, 2021, p. 125; Hess, 2021). We recommend that individuals and organizations listen to stakeholders (i.e., stigmatized groups) to understand and meet evolving needs with identity safety cues, create infrastructure that reinforces their values conveyed through cues, and contemplate potential pitfalls of implementing identity safety cues.

Consult Stigmatized Stakeholders. Some popular attempts at identity safety cues garnered criticism from the very populations they intended to support-illuminating the importance of evaluating stigmatized groups' perspectives on inclusion and diversity efforts. For example, companies often adopt public-facing Pride symbols (e.g., rainbow flags) in advertising while privately contributing to anti-gay agendas (a phenomenon called rainbow capitalism; Falco 
\& Gandhi, 2020), White people's wearing of safety pins after the 2016 U.S. Presidential Election to signal interracial allyship was deemed performative and empty (e.g., Henry, 2016), the decision among multiple cities to paint Black Lives Matter murals on their streets while maintaining hostile police-community relations has been met with calls of hypocrisy (e.g., King, 2020), and a top-down approach to implementing women-targeted diversity initiatives (e.g., the presence of women-centered affiliative groups) can backfire for women (Cundiff et al., 2018). We thus recommend that the actions of individuals and organizations to implement identity safety cues should be reviewed by intended targets of the cue, via informal feedback, surveys, or community liaisons and advisory boards. The purpose of identity safety cues is to actually transform environments, not merely to gesture or perform one's good intentions. To achieve the former goal, the perspectives of intended targets of cues must be prioritized.

Reinforce Authenticity of Identity Safety Cues. What happens when situational cues instill expectations that are unmet or violated? A crucial direction for the identity safety cue literature is to acknowledge that negative psychological experiences may arise when the values communicated by safety cues fail to be upheld. For example, Kroeper and colleagues (2020) found that portraying "counterfeit diversity" (i.e., organizations advertising gender diversity that is not represented in reality) can cause social identity threat among women and lead women and men to lose interest in the organization. Cues risk being perceived as dishonest when the reality of a setting for stigmatized groups contradicts the safety projected by the cues. For example, a major limitation to minority representation as a cue is that it requires members of a stigmatized group to be present in the first place (e.g., as employees, students, role models). It may seem challenging to recruit diversity without diversity. For this reason, some organizations "oversell" or falsely present demographic representation, such as advertising more employees from an underrepresented group than actually exist. The false information eventually backfires (Kroeper et al., 2020; Wilton et al., 2020; Windscheid et al., 2016). As another example, an environmental feature (e.g., a Black Lives Matter sign) or anti-racist diversity philosophy in a 
Psychology Department may intend to present as safety cues but exist in a space that historically undermines and excludes Black faculty, students, and participants in the scientific process (Dupree \& Boykin, 2021; Roberts et al., 2020). If a Black student encounters a racist professor within this particular Psychology department, how might their trust and feelings of belonging toward the department as a whole be compromised? This question highlights the need to assess cue efficacy in more complex and externally valid ways given that identity safety cues interact with other sources of information (e.g., other safety or threat experiences) in the real world.

Dishonest or counterfeit diversity initiatives pose an ethical dilemma as to whether individuals and organizations should make places "feel safe" that may not be safe. Further, displaying identity safety cues without structures in place to ensure safety could weaken cue efficacy if individuals become desensitized to cues and no longer perceive them as reliable information (e.g., rainbow washing; Hess, 2021). For instance, commonplace diversity philosophies could lose impact when people frequently encounter stated values that do not reflect reality. We thus advocate for authentic cues to signal the genuine and trusted commitment to inclusion (see Kroeper et al., 2020). To establish authentic cues, we recommend that individuals and organizations do not employ identity safety cues liberally nor without careful deliberation. To instill authenticity, cues should be endorsed by people who hold power (e.g., managers, leaders) as well as by the collective body (e.g., the workforce, student body), and cues should be paired with other diversity initiatives.

Consider Potential Pitfalls: Dominant Groups' Reactions. Though identity safety cue research centers stigmatized groups' responses, researchers also consider how cues affect dominant groups. Some studies suggest that dominant groups similarly benefit from the creation of equitable and inclusive environments. Women and men preferred a non-stereotypical computer science environment to a stereotypical one (a test of environmental features; Cheryan et al., 2009), and the presence of a workplace's gender-inclusivity policy was associated with 
less social identity threat among male workers (a test of diversity philosophies and programming; Hall et al., 2018). In contrast, if identity safety cues incite negative reactions from dominant groups, they may paradoxically harm stigmatized groups. For example, male participants disliked a non-stereotypical computer science classroom when it appeared "too" feminine (Cheryan et al., 2009), and White people perceived some organizations as exclusionary when diversity policies were present (Dover et al., 2016; Plaut et al., 2011). In situations in which cues trigger negative reactions from dominant groups, it is critical for researchers to find strategies that curb such reactions so that cue implementation does not inadvertently create more hostile intergroup interactions or environments. Dominant groups' perspectives can help researchers to anticipate and avoid potential ironic or backfiring effects of diversity initiatives (Bezrukova et al., 2016; Kaiser et al., 2013).

This review revealed several cases in which members of dominant groups were not harmed by efforts to enhance stigmatized groups' safety. Findings within this review should thus lessen concerns that identity safety cues targeting stigmatized groups induce identity threat among dominant groups. White men did not view companies with gender and racial diversity as any less procedurally fair or inclusive than companies without diversity (Chaney et al., 2016), gender-inclusive bathrooms in workplaces did not impact threat or safety of White cisgender men (Chaney \& Sanchez, 2018), the relationship between gender-inclusive workplace policies and men's social identity threat was insignificant (Hall et al., 2018), an evaluator's belief in gender stereotypes and the gender composition of the room did not affect men's test performance (Inzlicht \& Ben-Zeev, 2000; Wout et al., 2009), perceiving a company as having lower or higher diversity values did not impact White people's attendance at work (Avery et al., 2007), an inclusive diversity statement on a gym brochure was unrelated to (heterosexual) men's intentions to join the gym (Cunningham \& Melton, 2014), and stereotypes of computer science majors (i.e., "geeky") and the design of STEM spaces had little bearing on men's interest in computer science (e.g., Cheryan et al., 2009, 2013). Although cues cause can 
positive or negative reactions among members of dominant groups in some cases, the most common dominant group reaction to identity safety cues appears to be no reaction at all (for deeper discussion, see Ballinger \& Crocker, 2021).

\section{Limitations}

Though this review is the first to synthesize the identity safety cue literature and provides a foundation from which intersectional and translational research can continue, it is not without some limitations. First, although our search was thorough, it is possible related research exists beyond the present review. Nevertheless, we predict the taxonomy would still be valid because, even as new papers have emerged since our initial screening of articles, new research falls within these cue types. Put simply, unless a new type of identity safety cue surfaces and establishes a literature of supporting evidence, we trust the taxonomy is representative of the current science. However, there are other limitations related to our searching strategies: We narrowed our scope to gender and race because our initial assessment of the literature revealed gender and race to be the focus in nearly all cases. Other identities, such as sexual orientation, may have a literature developing but such studies would be overshadowed by the overrepresentation of gender and race here; thus, we tailored this review to specifically address identity safety cues that target people's gender or race which limits the generalizability of this taxonomy. Further, the chosen language of "safety cue" and keywords to reflect that phrasing likely directed us to social psychological literature and literature that prioritizes stigmatized groups' experiences. It is always possible that related concepts exist within other disciplines or operate within the context of dominant groups' psychological experiences; however, based on our keywords and search procedures, it is unlikely we would have discovered research that employs different language and terminology to refer to identity safety cues or focuses on dominant groups' experiences.

Finally, we emphasize that conclusions drawn in this article are bounded by the evidence that exists. The identity safety cue research is promising and enlarging, but as we 
have noted previously, there is a great need for attention on how identity safety cues interact with one another. Any such claims about the interplay between cues (e.g., which cues boost each other, take precedent, or cancel each other out) are largely speculative unless otherwise specified with supporting citation. In real-world situations, members of stigmatized groups will use multiple sources of information to form impressions of an environment and the people in it, and the overreliance on laboratory-based experimental studies perhaps sacrifices the reality of cues (i.e., their cooccurrence with other signals of safety and threat) for a researcher's need for scientific rigor and control in study design. Though it would be premature to model the interplay of different cues based on the status of the literature, we hope the growth of identity safety cue research allows for a more complex, interconnected modeling of how cues operate in the near future.

\section{Conclusion}

How can individuals and organizations create environments that promote the inclusion of stigmatized groups? By analyzing the identity safety cue literature, we identified four categories through which diversity and inclusion goals may be met. The reviewed research in support of identity safety cues provides needed evidence-based suggestions for improving inclusion and diversity. That is, tools exist for strengthening identity safety (e.g., belonging, trust, comfort, interest, performance), and we suggest that the expansion and application of these tactics will build on an already strong body of literature focused on gender- and race-based safety. For well-intentioned individuals and organizations who seek to identify "what works" for garnering the participation and interest of stigmatized groups, we hope this review illuminates the most tested strategies for doing so. 
Figure 1. Flowchart of Article Selection Process.

Identification of Articles Using Databases
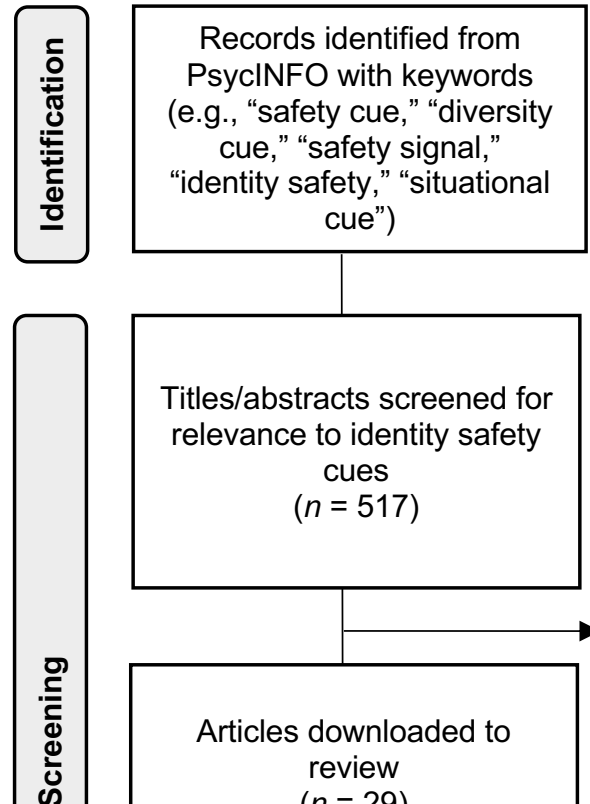

Titles/abstracts screened for relevance to identity safety

$$
(n=517)
$$

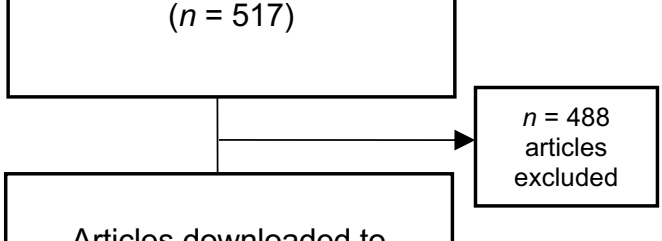

ভั

Articles downloaded to

$$
\text { review }
$$

$(n=29)$

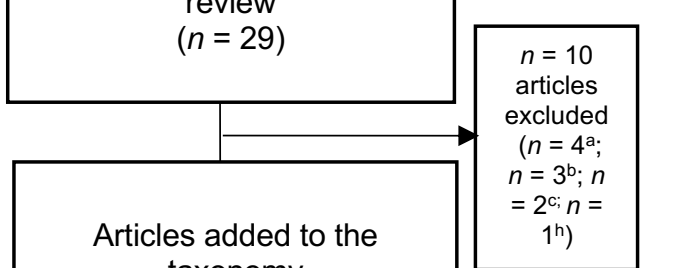

h)

$$
(n=19)
$$$$
(n=19)
$$

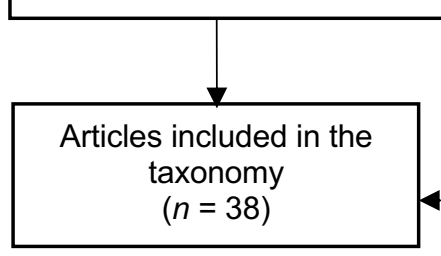

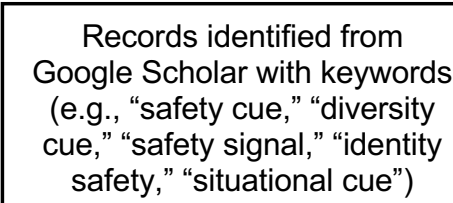

safety," "situational cue")
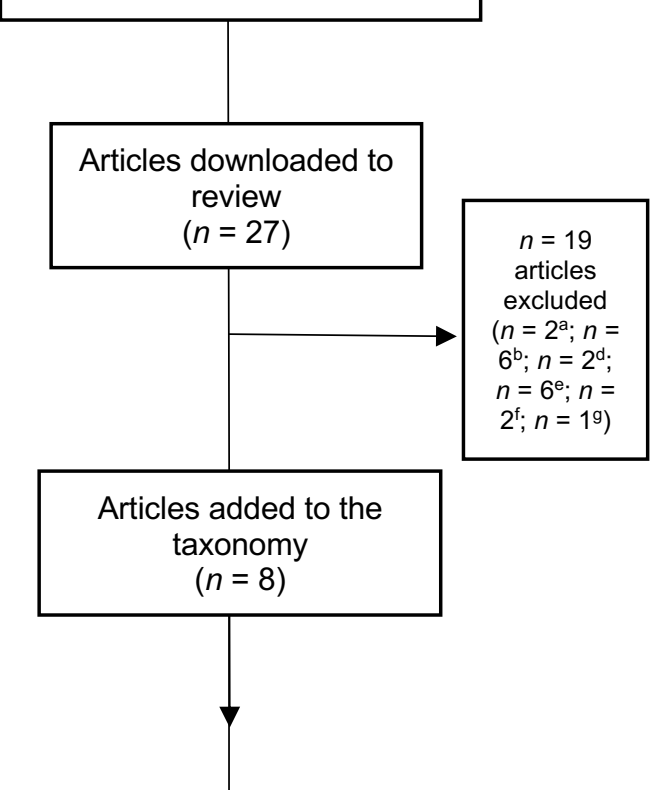

Note: Reasons for exclusion included: ${ }^{a}=$ Unrelated to cues; ${ }^{b}=$ About threat only; ${ }^{c}=$ Unrelated to identity safety; ${ }^{d}=$ Duplicates; ${ }^{e}=$ Not empirical; ${ }^{\mathrm{f}}=$ Dissertation/Thesis; ${ }^{\mathrm{g}}=$ Unrelated to stigmatized groups; ${ }^{\mathrm{h}}=$ Unrelated to target groups (i.e., by gender or race) 


\section{Table 1}

Classifications of Cues, Definitions, Operationalizations, and Citations

\begin{tabular}{|c|c|c|c|}
\hline Cue Type & Definition & Example Operationalization & Example Research \\
\hline $\begin{array}{l}\text { Minority } \\
\text { Representation }\end{array}$ & $\begin{array}{l}\text { The presence of } \\
\text { stigmatized groups, } \\
\text { either by number (e.g., } \\
\text { ratios), rank (e.g., role } \\
\text { models), or affiliation } \\
\text { (e.g., networks) }\end{array}$ & $\begin{array}{l}\text { High versus low amounts } \\
\text { of employees belonging to } \\
\text { the stigmatized group } \\
\text { (e.g., Black employees) in } \\
\text { a fictional company's } \\
\text { brochure }\end{array}$ & $\begin{array}{l}\text { Chaney et al., 2018; Cipollina \& Sanchez, 2020; } \\
\text { Driskell \& Trawalter, 2021; Emerson \& Murphy, } \\
\text { 2015; Hall et al., 2018; Johnson et al., 2019; Kahn } \\
\text { et al., 2015; Lee \& Park, 2011; Murphy et al., 2007; } \\
\text { Pietri, Drawbaugh, et al., 2019; Pietri, Hennes, et } \\
\text { al., 2019; Pietri et al., 2018; Purdie-Vaughns et al., } \\
\text { 2008; Wilton et al., 2020; Wout et al., 2014; Wout et } \\
\text { al., 2010; Wout et al., } 2009\end{array}$ \\
\hline $\begin{array}{l}\text { Diversity Philosophies } \\
\text { and Programming }\end{array}$ & $\begin{array}{l}\text { An individual's or } \\
\text { organization's stated } \\
\text { claims or policies that } \\
\text { highlight their valuing of } \\
\text { diversity }\end{array}$ & $\begin{array}{l}\text { An organization's website } \\
\text { that includes their } \\
\text { philosophy on diversity } \\
\text { (e.g., a mission statement } \\
\text { or a values statement) }\end{array}$ & $\begin{array}{l}\text { Autin et al., 2014; Chaney et al., 2016; Cipollina \& } \\
\text { Sanchez, 2020; Cundiff et al., 2018; Cunningham \& } \\
\text { Melton, 2014; Emerson \& Murphy, 2015; Good et } \\
\text { al., 2020; Hall et al., 2018; Howansky et al., 2021; } \\
\text { Muenks et al., 2020; Purdie-Vaughns et al., 2008; } \\
\text { Wilton et al., 2020; Wilton et al., } 2015\end{array}$ \\
\hline
\end{tabular}




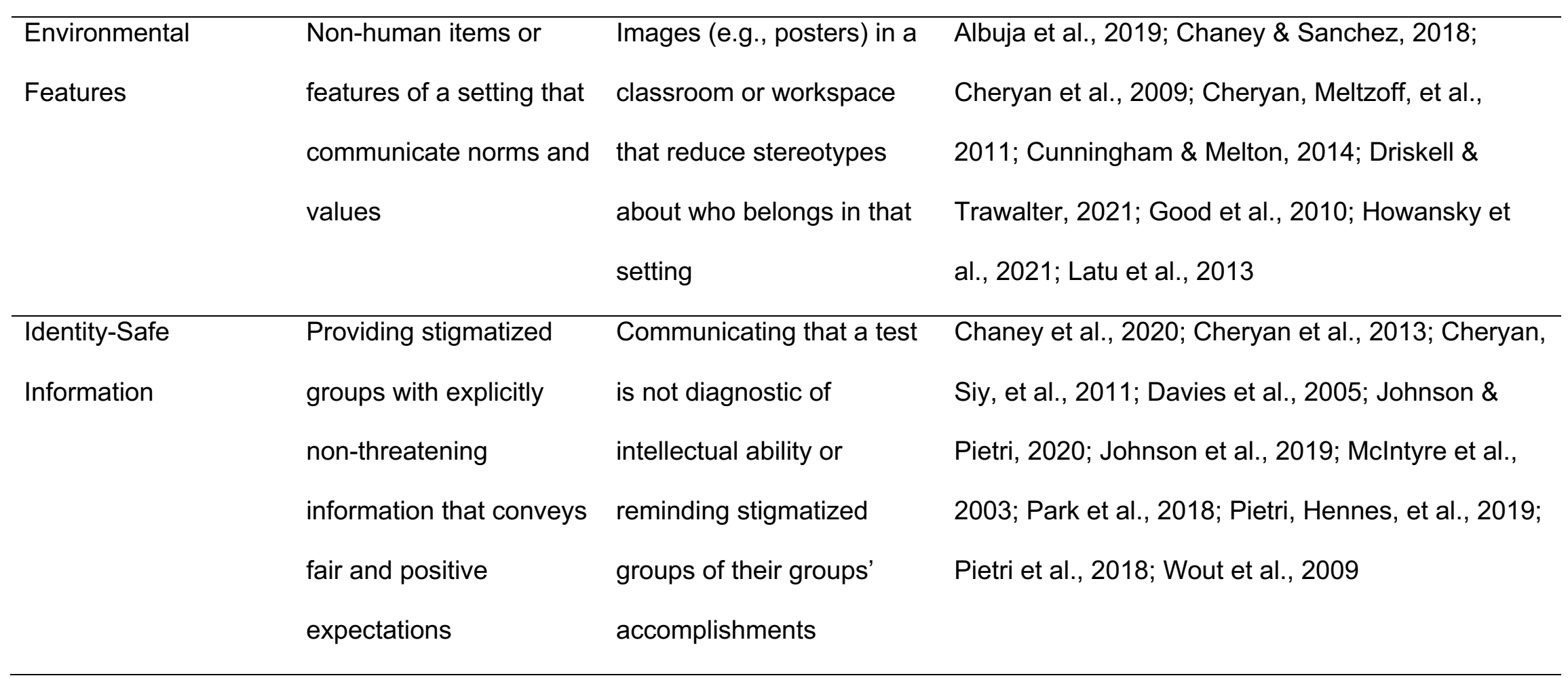




\section{References}

Albuja, A. F., Sanchez, D. T., Lee, S. J., Lee, J. Y., \& Yadava, S. (2019). The effect of paternal cues in prenatal care settings on men's involvement intentions. PloS One, 14(5), e0216454. https://doi.org/10.1371/journal.pone.0216454

Aronson, J., \& McGlone, M. S. (2009). Stereotype and social identity threat. In T. D. Nelson (Ed.), Handbook of prejudice, stereotyping, and discrimination (pp. 153-178). Psychology Press.

Autin, F., Branscombe, N. R., \& Croizet, J. C. (2014). Creating, closing, and reversing the gender gap in test performance: How selection policies trigger social identity threat or safety among women and men. Psychology of Women Quarterly, 38(3), 327-339. https://doi.org/10.1177/0361684313510485

Avery, D. R., McKay, P. F., Wilson, D. C., \& Tonidandel, S. (2007). Unequal attendance: The relationships between race, organizational diversity cues, and absenteeism. Personnel Psychology, 60(4), 875-902. https://doi.org/10.1111/j.1744-6570.2007.00094.x

Ballinger, T., \& Crocker, J. (2021). Understanding Whites' perceptions of multicultural policies: A (non)zero-sum framework? Journal of Personality and Social Psychology, 120(5), 12311260. https://doi.org/10.1037/pspi0000315

Bergsieker, H. B., Shelton, J. N., \& Richeson, J. A. (2010). To be liked versus respected:

Divergent goals in interracial interactions. Journal of Personality and Social Psychology, 99(2), 248-264. https://doi.org/10.1037/a0018474

Bezrukova, K., Spell, C. S., Perry, J. L., \& Jehn, K. A. (2016). A meta-analytical integration of over 40 years of research on diversity training evaluation. Psychological Bulletin, 142(11), 1227-1274. https://doi.org/10.1037/bul0000067

Bitterman, A. (2021). The rainbow connection: A time-series study of rainbow flag display across nine Toronto neighborhoods. In A. Bitterman \& D. B. Hess (Eds.), The life and afterlife of gay neighborhoods: Renaissance and resurgence (pp. 117-137). Springer. 
Bowleg, L. (2008). “When Black+lesbian+woman \# Black lesbian woman”: The methodological challenges of qualitative and quantitative intersectionality research. Sex Roles, 59(5-6), 312-325. https://doi.org/10.1007/s11199-008-9400-z

Brannon, T. N., Carter, E. R., Murdock- Perriera, L. A., \& Higginbotham, G. D. (2018). From backlash to inclusion for all: Instituting diversity efforts to maximize benefits across group lines. Social Issues and Policy Review, 12, 57-90. https://doi.org/10.1111/sipr.12040

Branscombe, N. R., Ellemers, N., Spears, R., \& Doosje, B. (1999). The context and content of social identity threat. In N. Ellemers, R. Spears, \& B. Doosje (Eds.), Social identity: Context, commitment, content (pp. 35-58). Blackwell Science.

Braun, V., \& Clarke, V. (2006). Using thematic analysis in psychology. Qualitative Research in Psychology, 3(2), 77-101. https://doi.org/10.1191/1478088706qp063oa

Browman, A. S., \& Destin, M. (2016). The effects of a warm or chilly climate toward socioeconomic diversity on academic motivation and self-concept. Personality and Social Psychology Bulletin, 42(2), 172-187. https://doi.org/10.1177/0146167215619379

Buchanan, N. T., \& Wiklund, L. O. (2021). Intersectionality research in psychological science: Resisting the tendency to disconnect, dilute, and depoliticize. Research on Child and Adolescent Psychopathology, 49(1), 25-31. https://doi.org/10.1007/s10802-020-00748-y

Cahan, E. (2020). Amid protests against racism, scientists move to strip offensive names from journals, prizes, and more. Science. https://doi.org/10.1126/science.abd6441

Carter, E. R., Onyeador, I. N., \& Lewis, N. A., Jr. (2020). Developing \& delivering effective antibias training: Challenges \& recommendations. Behavioral Science \& Policy 6(1), 57-70. https://doi.org/10.1353/bsp.2020.0005

Chamberlain, A. (2019). Glassdoor's job and hiring trends for 2020. Glassdoor Economic Research.https://www.glassdoor.com/research/app/uploads/sites/2/2019/11/Job_Hiring_ Trends_2020-FINAL-1-1.pdf 
Chaney, K. E., \& Sanchez, D. T. (2018). Gender-inclusive bathrooms signal fairness across identity dimensions. Social Psychological and Personality Science, 9(2), 245-253. https://doi.org/10.1177/1948550617737601

Chaney, K. E., Sanchez, D. T., \& Remedios, J. D. (2016). Organizational identity safety cue transfers. Personality and Social Psychology Bulletin, 42(11), 1564-1576. https://doi.org/10.1177/0146167216665096

Chaney, K. E., Sanchez, D. T., \& Remedios, J. D. (2018). We are in this together: How the presence of similarly stereotyped allies buffer against identity threat. Journal of Experimental Social Psychology, 79, 410-422. https://doi.org/10.1016/j.jesp.2018.09.005

Chaney, K. E., Sanchez, D. T., \& Remedios, J. D. (2020). Dual cues: Women of color anticipate both gender and racial bias in the face of a single identity cue. Group Processes \& Intergroup Relations, 1368430220942844. https://doi.org/10.1177/1368430220942844

Chang, E. H., Milkman, K. L., Gromet, D. M., Rebele, R. W., Massey, C., Duckworth, A. L., \& Grant, A. M. (2019). The mixed effects of online diversity training. Proceedings of the National Academy of Sciences, 116(16), 201816076. https://doi.org/10.1073/pnas.1816076116

Chapman, H., \& Coffé, H. (2016). Changing Facebook profile pictures as part of a campaign: Who does it and why? Journal of Youth Studies, 19(4), 483-500. https://doi.org/10.1080/13676261.2015.1083962

Cheryan, S., Meltzoff, A. N., \& Kim, S. (2011). Classrooms matter: The design of virtual classrooms influences gender disparities in computer science classes. Computers \& Education, 57(2), 1825-1835. https://doi.org/10.1016/j.compedu.2011.02.004

Cheryan, S., Plaut, V. C., Davies, P. G., \& Steele, C. M. (2009). Ambient belonging: how stereotypical cues impact gender participation in computer science. Journal of Personality and Social Psychology, 97(6), 1045-1060. https://doi.org/10.1037/a0016239 
Cheryan, S., Plaut, V. C., Handron, C., \& Hudson, L. (2013). The stereotypical computer scientist: Gendered media representations as a barrier to inclusion for women. Sex Roles, 69(1-2), 58-71. https://doi.org/10.1007/s11199-013-0296-x

Cheryan, S., Siy, J. O., Vichayapai, M., Drury, B. J., \& Kim, S. (2011). Do female and male role models who embody STEM stereotypes hinder women's anticipated success in STEM? Social Psychological and Personality Science, 2(6), 656-664.

https://doi.org/10.1177/1948550611405218

Cipollina, R., \& Sanchez, D. T. (2019). Reducing health care disparities through improving trust: An identity safety cues intervention for stigmatized groups. Translational Issues in Psychological Science, 5(4), 315-325. https://doi.org/10.1037/tps0000207

Cipollina, R., \& Sanchez, D. T. (2020). Racial identity safety cues and healthcare provider expectations. Stigma and Health. Advanced online publication. https://doi.org/10.1037/sah0000265

Cipollina, R., \& Sanchez, D. T. (2021). Identity cues influence sexual minorities' anticipated treatment and disclosure intentions in healthcare settings: Exploring a multiple pathway model. Journal of Health Psychology. Advanced online publication. https://doi.org/10.1177/1359105321995984

Cole, E. R. (2009). Intersectionality and research in psychology. American Psychologist, 64(3), 170-180. https://doi.org/10.1037/a0014564

Collins, P. H. (2000). Black feminist thought: Knowledge, consciousness, and the politics of empowerment (2nd ed.). Routledge.

Crenshaw, K. (1989). Demarginalizing the intersection of race and sex: A Black feminist critique of antidiscrimination doctrine, feminist theory and antiracist politics. The University of Chicago Legal Forum, 140, 139-167. 
Crenshaw, K. (1991). Mapping the margins: Intersectionality, identity politics, and violence against women of color. Stanford Law Review, 43(6), 1241-1299. https://doi.org/10.2307/1229039

Cundiff, J. L., Ryuk, S., \& Cech, K. (2018). Identity-safe or threatening? Perceptions of womentargeted diversity initiatives. Group Processes \& Intergroup Relations, 21(5), 745-766. https://doi.org/10.1177/1368430217740434

Cunningham, G. B., \& Melton, E. N. (2014). Signals and cues: LGBT inclusive advertising and consumer attraction. Sport Marketing Quarterly, 23(1), 37-46.

Dasgupta, N. (2011). Ingroup experts and peers as social vaccines who inoculate the selfconcept: The stereotype inoculation model. Psychological Inquiry, 22(4), 231-246. https://doi.org/10.1080/1047840X.2011.607313

Davies, P. G., Spencer, S. J., \& Steele, C. M. (2005). Clearing the air: Identity safety moderates the effects of stereotype threat on women's leadership aspirations. Journal of Personality and Social Psychology, 88(2), 276-287. https://doi.org/10.1037/0022-3514.88.2.276

Dover, T. L., Major, B., \& Kaiser, C. R. (2016). Members of high-status groups are threatened by pro-diversity organizational messages. Journal of Experimental Social Psychology, 62, 58-67. https://doi.org/10.1016/j.jesp.2015.10.006

Driskell, S., \& Trawalter, S. (2021). Race, architecture, and belonging: Divergent perceptions of Antebellum architecture. Collabra, 7(1), 21192. https://doi.org/10.1525/collabra.21192

Dupree, C. H., \& Boykin, C. M. (2021). Racial inequality in Academia: Systemic origins, modern challenges, and policy recommendations. Policy Insights from the Behavioral and Brain Sciences, 8(1), 133-141. https://doi.org/10.1177/2347631120983481

Ellemers, N., Spears, R., \& Doosje, B. (2002). Self and social identity. Annual Review of Psychology, 53(1), 161-186. https://doi.org/10.1146/annurev.psych.53.100901.135228

Emerson, K. T. U., \& Murphy, M. C. (2014). Identity threat at work: How social identity threat and situational cues contribute to racial and ethnic disparities in the workplace. Cultural 
Diversity and Ethnic Minority Psychology, 20(4), 508-520. https://doi.org/10.1037/a0035403

Emerson, K. T. U., \& Murphy, M. C. (2015). A company I can trust? Organizational lay theories moderate stereotype threat for women. Personality and Social Psychology Bulletin, 41(2), 295-307. https://doi.org/10.1177/0146167214564969

Engelhard, I. M., van Uijen, S. L., van Seters, N., \& Velu, N. (2015). The effects of safety behavior directed towards a safety cue on perceptions of threat. Behavior Therapy, 46(5), 604-610. https://doi.org/10.1016/j.beth.2014.12.006

Ereshefsky, M. (2000). The poverty of the Linnaean hierarchy: A philosophical study of biological taxonomy. Cambridge University Press. https://doi.org/10.1017/CBO9780511498459

Falco, A., \& Gandhi, S. (2020). The rainbow business. Eidos, 9(1), 104-107. http://xaviers.edu.in/ojs3/index.php/eidos/article/view/109

Fingerhut, A. W., \& Abdou, C. M. (2017). The role of healthcare stereotype threat and social identity threat in LGB health disparities. Journal of Social Issues, 73(3), 493-507. https://doi.org/10.1111/josi.12228

Frederiksen, N. (1972). Toward a taxonomy of situations. American Psychologist, 27(2), 114123. https://doi.org/10.1037/h0032705

Good, J. J., Bourne, K. A., \& Drake, R. G. (2020). The impact of classroom diversity philosophies on the STEM performance of undergraduate students of color. Journal of Experimental Social Psychology, 91, 104026. https://doi.org/10.1016/j.jesp.2020.104026

Good, J. J., Woodzicka, J. A., \& Wingfield, L. C. (2010). The effects of gender stereotypic and counter-stereotypic textbook images on science performance. Journal of Social Psychology, 150(2), 132-147. https://doi.org/10.1080/00224540903366552

Grzanka, P. R. (2018). Intersectionality and feminist psychology: Power, knowledge, and process. In C. B. Travis, J. W. White, A. Rutherford, W. S. Williams, S. L. Cook, \& K. F. 
Wyche (Eds.), APA handbook of the psychology of women (pp. 585-602). American Psychological Association.

Grzanka, P. R., Flores, M. J., VanDaalen, R. A., \& Velez, G. (2020). Intersectionality in psychology: Translational science for social justice. Translational Issues in Psychological Science, 6(4), 304-313. http://dx.doi.org/10.1037/tps0000276

Hall, W., Schmader, T., Aday, A., Inness, M., \& Croft, E. (2018). Climate control: The relationship between social identity threat and cues to an identity-safe culture. Journal of Personality and Social Psychology, 115(3), 446-467.

http://dx.doi.org/10.1037/pspi0000137

Harding, S. (2004). Introduction: Standpoint theory as a site of political, philosophic, and scientific debate. In S. Harding (Ed.), The feminist standpoint theory reader: Intellectual and political controversies (pp. 1-16). Routledge.

Henry, P. (2016). Safety pins: The bat signal of White guilt for Donald Trump's America. https://www.mic.com/articles/1593 65/safety-pins-the-batsignal-of-white-guilt-in-donaldtrump-s-America

Hess, A. J. (2021). "A rainbow logo isn't enough"—why LGBTQ workers say some Pride celebrations fall short. https://www.cnbc.com/2021/06/04/why-lgbtq-workers-say-somepride-celebrations-fall-short.html

hooks, B. (1984). Feminist theory: From margin to center. Pluto Press.

Howansky, K., Maimon, M., \& Sanchez, D. T. (2021). Identity safety cues predict instructor impressions, belonging, and absences in the psychology classroom. Teaching of Psychology. https://doi.org/10.1177/0098628321990362

Hunger, J. M., Major, B., Blodorn, A., \& Miller, C. T. (2015). Weighed down by stigma: How weight-based social identity threat contributes to weight gain and poor health. Social and Personality Psychology Compass, 9(6), 255-268. https://doi.org/10.1111/spc3.12172 
Inzlicht, M., \& Ben-Zeev, T. (2000). A threatening intellectual environment: Why females are susceptible to experiencing problem-solving deficits in the presence of males. Psychological Science, 11(5), 365-371. https://doi.org/10.1111/1467-9280.00272

Inzlicht, M., Tullett, A. M., Legault, L., \& Kang, S. K. (2011). Lingering effects: Stereotype threat hurts more than you think. Social Issues and Policy Review, 5(1), 227-256. https://doi.org/10.1111/j.1751-2409.2011.01031.x

John, O. P. (1989). Towards a taxonomy of personality descriptors. In D. M. Buss \& N. Cantor N. (Eds.), Personality psychology (pp. 261-271). Springer. https://doi.org/10.1007/978-1$\underline{4684-0634-4 \quad 20}$

Johnson, I. R., \& Pietri, E. S. (2020). An ally you say? Endorsing White women as allies to encourage perceptions of allyship and organizational identity-safety among Black women. Group Processes \& Intergroup Relations. https://doi.org/10.1177/1368430220975482

Johnson, I. R., Pietri, E. S., Fullilove, F., \& Mowrer, S. (2019). Exploring identity-safety cues and allyship among Black women students in STEM environments. Psychology of Women Quarterly, 43(2), 131-150. https://doi.org/10.1177/0361684319830926

Kahn, K. B., Unzueta, M. M., Davies, P. G., Alston, A. T., \& Lee, J. K. (2015). Will you value me and do I value you? The effect of phenotypic racial stereotypicality on organizational evaluations. Journal of Experimental Social Psychology, 59, 130-138. https://doi.org/10.1016/j.jesp.2015.03.008

Kaiser, C. R., Major, B., Jurcevic, I., Dover, T. L., Brady, L. M., \& Shapiro, J. R. (2013).

Presumed fair: Ironic effects of organizational diversity structures. Journal of Personality and Social Psychology, 104(3), 504-519. https://doi.org/10.1037/a0030838

Kaiser, C. R., Vick, S. B., \& Major, B. (2006). Prejudice expectations moderate preconscious attention to cues that are threatening to social identity. Psychological Science, 17(4), 332-338. https://doi.org/10.1111/j.1467-9280.2006.01707.x 
Kalev, A., Dobbin, F., \& Kelly, E. (2006). Best practices or best guesses? Assessing the efficacy of corporate affirmative action and diversity policies. American Sociological Review, 71(4), 589-617. https://doi.org/10.1177/000312240607100404

King, M. (2020). 'It's not enough': Activists say Black Lives Matter murals are empty gesture. https://www.politico.com/news/2020/07/19/black-lives-matter-murals-369091

Kroeper, K. M., Williams, H. E., \& Murphy, M. C. (2020). Counterfeit diversity: How strategically misrepresenting gender diversity dampens organizations' perceived sincerity and elevates women's identity threat concerns. Journal of Personality and Social Psychology. https://doi.org/10.1037/pspi0000348

Lai, C. K., Marini, M., Lehr, S. A., Cerruti, C., Shin, J.-E. L., Joy-Gaba, J. A., Ho, A. K., Teachman, B. A., Wojcik, S. P., Koleva, S. P., Frazier, R. S., Heiphetz, L., Chen, E. E., Turner, R. N., Haidt, J., Kesebir, S., Hawkins, C. B., Schaefer, H. S., Rubichi, S., ... Nosek, B. A. (2014). Reducing implicit racial preferences: I. A comparative investigation of 17 interventions. Journal of Experimental Psychology: General, 143(4), 1765-1785. https://doi.org/10.1037/a0036260

Latu, I. M., Mast, M. S., Lammers, J., \& Bombari, D. (2013). Successful female leaders empower women's behavior in leadership tasks. Journal of Experimental Social Psychology, 49(3), 444-448. https://doi.org/10.1016/j.jesp.2013.01.003

Lee, J. E. R., \& Park, S. G. (2011). "Whose second life is this?" How avatar-based racial cues shape ethno-racial minorities' perception of virtual worlds. Cyberpsychology, Behavior, and Social Networking, 14(11), 637-642. https://doi.org/10.1089/cyber.2010.0501

Legault, L., Gutsell, J. N., \& Inzlicht, M. (2011). Ironic effects of antiprejudice messages: How motivational interventions can reduce (but also increase) prejudice. Psychological Science, 22, 1472-1477. https://doi.org/10.1177/0956797611427918

Leong, N. (2013). Racial capitalism. Harvard Law Review, 126(8), 2151-2226. 
Maass, A., Cadinu, M., Guarnieri, G., \& Grasselli, A. (2003). Sexual harassment under social identity threat: The computer harassment paradigm. Journal of Personality and Social Psychology, 85(5), 853-870. https://doi.org/10.1037/0022-3514.85.5.853

Mackey, C. D., Silver, C. F., Rios, K., Cowgill, C. M., \& Hood, R. W. (2020). Concealment of nonreligious identity: Exploring social identity threat among atheists and other nonreligious individuals. Group Processes \& Intergroup Relations, 24(5), 860-877. https://doi.org/10.1177/1368430220905661

Major, B., Mendes, W. B., \& Dovidio, J. F. (2013). Intergroup relations and health disparities: A social psychological perspective. Health Psychology, 32(5), 514-524. https://doi.org/10.1037/a0030358

Major, B., \& Schmader, T. (2018). Stigma, social identity threat, and health. In B. Major, J. F. Dovidio, \& B. G. Link (Eds.), The Oxford handbook of stigma, discrimination, and health (pp. 85-103). Oxford University Press.

Matsick, J. L., Kim, L. M., \& Kruk, M. (2020). Facebook LGBTQ pictivism: The effects of women's rainbow profile filters on sexual prejudice and online belonging. Psychology of Women Quarterly, 44(3), 342-361. https://doi.org/10.1177/0361684320930566

Matsick, J. L., Kruk, M., Palmer, L., Layland, E., \& Salomaa, A. (under review). Extending the social category label effect to stigmatized groups: Lesbian and gay people's reactions to "homosexual" as a label.

McCormick-Huhn, K., Warner, L. R., Settles, I. H., \& Shields, S. A. (2019). What if psychology took intersectionality seriously? Changing how psychologists think about participants. Psychology of Women Quarterly, 43(4), 445-456. https://doi.org/10.1177/0361684319866430

Mclntyre, R. B., Paulson, R. M., \& Lord, C. G. (2003). Alleviating women's mathematics stereotype threat through salience of group achievements. Journal of Experimental Social Psychology, 39(1), 83-90. https://doi.org/10.1016/S0022-1031(02)00513-9 
Mendoza-Denton, R., Downey, G., Purdie, V. J., Davis, A., \& Pietrzak, J. (2002). Sensitivity to status-based rejection: Implications for African American students' college experience. Journal of Personality and Social Psychology, 83(4), 896-918. https://doi.org/10.1037/0022-3514.83.4.896

Mercier, E. M., Barron, B., \& O'Connor, K. M. (2006). Images of self and others as computer users: The role of gender and experience. Journal of Computer Assisted Learning, 22, 335-348. https://doi.org/10.1111/j.1365-2729.2006.00182.x

Muenks, K., Canning, E. A., LaCosse, J., Green, D. J., Zirkel, S., Garcia, J. A., \& Murphy, M. C. (2020). Does my professor think my ability can change? Students' perceptions of their STEM professors' mindset beliefs predict their psychological vulnerability, engagement, and performance in class. Journal of Experimental Psychology: General, 149(11), 21192144. https://doi.org/10.1037/xge0000763

Murphy, M. C., Kroeper, K. M., \& Ozier, E. M. (2018). Prejudiced places: How contexts shape inequality and how policy can change them. Policy Insights from the Behavioral and Brain Sciences, 5(1), 66-74. https://doi.org/10.1177/2372732217748671

Murphy, M. C., Steele, C. M., \& Gross, J. J. (2007). Signaling threat: How situational cues affect women in math, science, and engineering settings. Psychological Science, 18(10), 879885. https://doi.org/10.1111/j.1467-9280.2007.01995.x

Murphy, M. C., \& Taylor, V. J. (2012). The role of situational cues in signaling and maintaining stereotype threat. In M. Inzlicht \& T. Schmader (Eds.), Stereotype threat: Theory, process, and application (pp. 17-33). Oxford University Press.

Nadal, K. L., Whitman, C. N., Davis, L. S., Erazo, T., \& Davidoff, K. C. (2016). Microaggressions toward lesbian, gay, bisexual, transgender, queer, and genderqueer people: A review of the literature. The Journal of Sex Research, 53(4-5), 488-508. https://doi.org/10.1080/00224499.2016.1142495 
Nash, J. D., Newberg, A., \& Awasthi, B. (2013). Toward a unifying taxonomy and definition for meditation. Frontiers in Psychology, 4, 1-18. https://doi.org/10.3389/fpsyg.2013.00806

Nosek, B. A., Spies, J. R., \& Motyl, M. (2012). Scientific utopia II. Restructuring incentives and practices to promote truth over publishability. Perspectives on Psychological Science, 7(6), 615-631. https://doi.org/10.1177/1745691612459058

O'Connor, C., \& Joffe, H. (2020). Intercoder reliability in qualitative research: Debates and practical guidelines. International Journal of Qualitative Methods, 19, 1-13. https://doi.org/10.1177/1609406919899220

Onyeador, I. N., Hudson, S. T. J., \& Lewis, N. A. (2021). Moving beyond implicit bias training: Policy insights for increasing organizational diversity. Policy Insights from the Behavioral and Brain Sciences, 8(1), 19-26. https://doi.org/10.1177/2372732220983840

Oswald, F., Stevens, S., Kruk, M., Murphy, C. I., \& Matsick, J. L. (Under review). Signaling sizeism: An assessment of body size-based safety and threat cues.

Overstreet, N. M., Rosenthal, L., \& Case, K. A. (2020). Intersectionality as a radical framework for transforming our disciplines, social issues, and the world. Journal of Social Issues, 76(4), 779-795. https://doi.org/10.1111/josi.12414

Oyserman, D., Uskul, A. K., Yoder, N., Nesse, R. M., \& Williams, D. R. (2007). Unfair treatment and self-regulatory focus. Journal of Experimental Social Psychology, 43(3), 505512. https://doi.org/10.1016/j.jesp.2006.05.014

Pachankis, J. E. (2007). The psychological implications of concealing a stigma: A cognitiveaffective-behavioral model. Psychological Bulletin, 133(2), 328-345. https://doi.org/10.1037/0033-2909.133.2.328

Page, M. J., McKenzie, J. E., Bossuyt, P. M., Boutron, I., Hoffman, T. C., Mulrow, C. D., Shamseer, L., Tetzlaff, J. M., Akl, E. A., Brennan, S. E., Chou, R., Glanville, J., Grimshaw, J. M., Hrobjartsson, A., Lalu, M. M., Li, T., Loder, E. W., Mayo-Wilson, E., McDonald, S., ... Moher, D. (2021). The PRISMA 2020 statement: An updated guideline 
for reporting systematic reviews. Systematic Reviews, 10, 1-11.

https://doi.org/10.1186/s13643-021-01626-4

Paluck, E. L., Porat, R., Clark, C. S., \& Green, D. P. (2021). Prejudice reduction: Progress and challenges. Annual Review of Psychology, 72(1), 1-28. https://doi.org/10.1146/annurevpsych-071620-030619

Park, L. E., Kondrak, C. L., Ward, D. E., \& Streamer, L. (2018). Positive feedback from male authority figures boosts women's math outcomes. Personality and Social Psychology Bulletin, 44(3), 359-383. https://doi.org/10.1177/0146167217741312

Patton, L. D., Sánchez, B., Mac, J., \& Stewart, D. L. (2019). An inconvenient truth about "progress": An analysis of the promises and perils of research on campus diversity initiatives. The Review of Higher Education, 42(5), 173-198. https://doi.org/10.1353/rhe.2019.0049

Pennington, C. R., Heim, D., Levy, A. R., \& Larkin, D. T. (2016). Twenty years of stereotype threat research: A review of psychological mediators. PloS ONE, 11(1), e0146487. https://doi.org/10.1371/journal.pone.0146487

Pietri, E. S., Drawbaugh, M. L., Lewis, A. N., \& Johnson, I. R. (2019). Who encourages Latina women to feel a sense of identity-safety in STEM environments? Journal of Experimental Social Psychology, 84, 103827. https://doi.org/10.1016/j.jesp.2019.103827

Pietri, E. S., Hennes, E. P., Dovidio, J. F., Brescoll, V. L., Bailey, A. H., Moss-Racusin, C. A., \& Handelsman, J. (2019). Addressing unintended consequences of gender diversity interventions on women's sense of belonging in STEM. Sex Roles, 80(9), 527-547. https://doi.org/10.1007/s11199-018-0952-2

Pietri, E. S., Johnson, I. R., \& Ozgumus, E. (2018). One size may not fit all: Exploring how the intersection of race and gender and stigma consciousness predict effective identity-safe cues for Black women. Journal of Experimental Social Psychology, 74, 291-306. https://doi.org/10.1016/j.jesp.2017.06.021 
Pinel, E. C. (1999). Stigma consciousness: The psychological legacy of social stereotypes. Journal of Personality and Social Psychology, 76(1), 114-128. https://doi.org/10.1037/0022-3514.76.1.114

Plaut, V. C., Garnett, F. G., Buffardi, L. E., \& Sanchez-Burks, J. (2011). "What about me?” Perceptions of exclusion and Whites' reactions to multiculturalism. Journal of Personality and Social Psychology, 101(2), 337-353. http://dx.doi.org/10.1037/a0022832

Purdie-Vaughns, V., \& Eibach, R. P. (2008). Intersectional invisibility: The distinctive advantages and disadvantages of multiple subordinate-group identities. Sex Roles, 59(5-6), 377-391. https://doi.org/10.1007/s11199-008-9424-4

Purdie-Vaughns, V., Steele, C. M., Davies, P. G., Ditlmann, R., \& Crosby, J. R. (2008). Social identity contingencies: How diversity cues signal threat or safety for African Americans in mainstream institutions. Journal of Personality and Social Psychology, 94(4), 615-630. https://doi.org/10.1037/0022-3514.94.4.615

Richeson, J. A., \& Shelton, J. N. (2007). Negotiating interracial interactions: Costs, consequences, and possibilities. Current Directions in Psychological Science, 16, 316320. https://doi.org/10.1111/j.1467-8721.2007.00528.x

Rickford, R. (2016). Black Lives Matter: Toward a modern practice of mass struggle. New Labor Forum, 25(1), 34-42. https://doi.org/10.1177/1095796015620171

Roberts, S. O., Bareket-Shavit, C., Dollins, F. A., Goldie, P. D., \& Mortenson, E. (2020). Racial inequality in psychological research: Trends of the past and recommendations for the future. Perspectives on Psychological Science, 15(6), 1295-1309.

\section{https://doi.org/10.1177/1745691620927709}

Roediger, D. (2005). What's wrong with these pictures? Race, narratives of admission, and the liberal representations of historically White colleges and universities. Washington University Journal of Law \& Policy, 18, 203-222. https://openscholarship.wustl.edu/law_journal_law_policy/vol18/iss1/9 
Rommes, E., Overbeek, G., Scholte, R., Engels, R., \& De Kemp, R. (2007). 'I'm not interested in computers': Gender-based occupational choices of adolescents. Information, Community, and Society, 10, 299-319. https://doi.org/10.1080/136911807014 09838

Sanchez, D. T., Chaney, K. E., Manuel, S. K., \& Remedios, J. D. (2018). Theory of prejudice and American identity threat transfer for Latino and Asian Americans. Personality and Social Psychology Bulletin, 44(7), 972-983. https://doi.org/10.1177/0146167218759288

Sanchez, D. T., Chaney, K. E., Manuel, S. K., Wilton, L. S., \& Remedios, J. D. (2017). Stigma by prejudice transfer: Racism threatens White women and sexism threatens men of color. Psychological Science, 28(4), 445-461. https://doi.org/10.1177/0956797616686218

Sandstrom, G. M., Schmader, T., Croft, A., \& Kwok, N. (2019). A social identity threat perspective on being the target of generosity from a higher status other. Journal of Experimental Social Psychology, 82, 98-114. https://doi.org/10.1016/j.jesp.2018.12.004

Scheepers, D., Ellemers, N., \& Sintemaartensdijk, N. (2009). Suffering from the possibility of status loss: Physiological responses to social identity threat in high status groups. European Journal of Social Psychology, 39(6), 1075-1092. https://doi.org/10.1002/ejsp.609

Schmidt, L. J., Belopolsky, A. V., \& Theeuwes, J. (2017). The time course of attentional bias to cues of threat and safety. Cognition and Emotion, 31(5), 845-857. https://doi.org/10.1080/02699931.2016.1169998

Settles, I. H., Warner, L. R., Buchanan, N. T., \& Jones, M. K. (2020). Understanding psychology's resistance to intersectionality theory using a framework of epistemic exclusion and invisibility. Journal of Social Issues, 76(4), 796-813. https://doi.org/10.1111/josi.12403 
Smith, D. (1987). The everyday world as problematic: A feminist methodology. In D. Smith (Ed.), The everyday world as problematic: A feminist sociology (pp. 105-146). Northeastern University Press.

Spencer, S. J., Logel, C., \& Davies, P. G. (2016). Stereotype threat. Annual Review of Psychology, 67(1), 1-23. https://doi.org/10.1146/annurev-psych-073115-103235

Spencer, S. J., Steele, C. M., \& Quinn, D. (1999). Stereotype threat and women's math performance. Journal of Experimental Social Psychology, 35(1), 4-28. https://doi.org/10.1006/jesp.1998.1373

Steele, C. M. (1997). A threat in the air: How stereotypes shape intellectual identity and performance. American Psychologist, 52(6), 613-629. https://doi.org/10.1037/0003066X.52.6.613

Steele, C. M. (2010). Whistling Vivaldi: How stereotypes affect us and what we can do. W.W. Norton \& Company.

Steele, C. M., \& Aronson, J. (1995). Stereotype threat and the intellectual test performance of African Americans. Journal of Personality and Social Psychology, 69(5), 797-811. https://doi.org/10.1037/0022-3514.69.5.797

Steele, C. M., Spencer, S. J., \& Aronson, J. (2002). Contending with group image: The psychology of stereotype and social identity threat. In M. P. Zanna (Ed.), Advances in experimental social psychology (Vol. 34, pp. 379-440). Emerald Publishing.

Sue, D. W., Capodilupo, C. M., Torino, G. C., Bucceri, J. M., Holder, A. M., Nadal, K. L., \& Esquilin, M. (2007). Racial microaggressions in everyday life: Implications for clinical practice. American Psychologist, 62(4), 271-286. https://doi.org/10.1037/0003$\underline{066 \times .62 .4 .271}$

Townsend, S. S. M., Major, B., Gangi, C. E., \& Mendes, W. B. (2011). From "in the air" to "under the skin": Cortisol responses to social identity threat. Personality and Social Psychology Bulletin, 37(2), 151-164. https://doi.org/10.1177/0146167210392384 
Trawalter, S., Hoffman, K., \& Palmer, L. (2021). Out of place: Socioeconomic status, use of public space, and belonging in higher education. Journal of Personality and Social Psychology, 120(1), 131-144. https://doi.org/10.1037/pspi0000248

Vorauer, J. D. (2006). An information search model of evaluative concerns in intergroup interaction. Psychological Review, 113(4), 862-886. https://doi.org/10.1037/0033295X.113.4.862

Walton, G. M., \& Cohen, G. L. (2007). A question of belonging: Race, social fit, and achievement. Journal of Personality and Social Psychology, 92(1), 82-96. https://doi.org/10.1037/0022-3514.92.1.82

Warner, L. R. (2008). A best practices guide to intersectional approaches in psychological research. Sex Roles, 59, 454-463. https://doi.org/10.1007/s11199-008-9504-5

Washington, E., \& Newport, F. (2017). Diversity and inclusion in the workplace after Trump Election. Gallup. https://www.gallup.com/workplace/236324/diversity-inclusionworkplace-trump-election.aspx

Wilton, L. S., Bell, A. N., Vahradyan, M., \& Kaiser, C. R. (2020). Show don't tell: Diversity dishonesty harms racial/ethnic minorities at work. Personality and Social Psychology Bulletin, 46(8), 1171-1185. https://doi.org/10.1177/0146167219897149

Wilton, L. S., Good, J. J., Moss-Racusin, C. A., \& Sanchez, D. T. (2015). Communicating more than diversity: The effect of institutional diversity statements on expectations and performance as a function of race and gender. Cultural Diversity and Ethnic Minority Psychology, 21(3), 315-325. https://doi.org/10.1037/a0037883

Windscheid, L., Bowes-Sperry, L., Kidder, D. L., Cheung, H. K., Morner, M., \& Lievens, F. (2016). Actions speak louder than words: Outsiders' perceptions of diversity mixed messages. The Journal of Applied Psychology, 101(9), 1329-1341. https://doi.org/10.1037/apl0000107 
Wout, D. A., Murphy, M. C., \& Barnett, S. (2014). When having Black friends isn't enough: How threat cues undermine safety cues in friendship formation. Social Psychological and Personality Science, 5(7), 844-851. https://doi.org/10.1177/1948550614535820

Wout, D. A., Murphy, M. C., \& Steele, C. M. (2010). When your friends matter: The effect of White students' racial friendship networks on meta-perceptions and perceived identity contingencies. Journal of Experimental Social Psychology, 46(6), 1035-1041. https://doi.org/10.1016/j.jesp.2010.06.003

Wout, D. A., Shih, M. J., Jackson, J. S., \& Sellers, R. M. (2009). Targets as perceivers: How people determine when they will be negatively stereotyped. Journal of Personality and Social Psychology, 96(2), 349-362. http://dx.doi.org/10.1037/a0012 